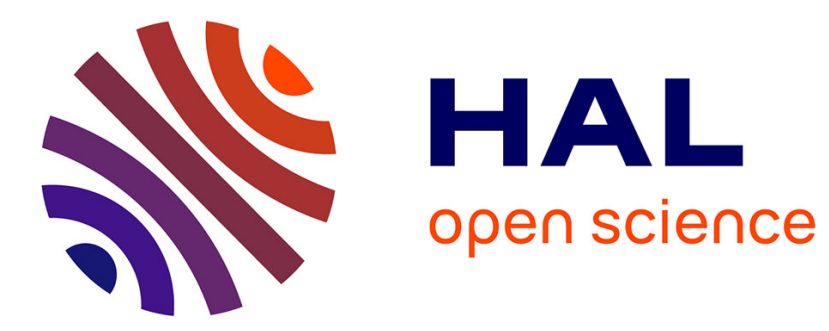

\title{
Strategic Communication Networks
}

Jeanne Hagenbach, Frédéric Koessler

\section{To cite this version:}

Jeanne Hagenbach, Frédéric Koessler. Strategic Communication Networks. 2009. halshs-00367692

\section{HAL Id: halshs-00367692 \\ https://shs.hal.science/halshs-00367692}

Submitted on 12 Mar 2009

HAL is a multi-disciplinary open access archive for the deposit and dissemination of scientific research documents, whether they are published or not. The documents may come from teaching and research institutions in France or abroad, or from public or private research centers.
L'archive ouverte pluridisciplinaire HAL, est destinée au dépôt et à la diffusion de documents scientifiques de niveau recherche, publiés ou non, émanant des établissements d'enseignement et de recherche français ou étrangers, des laboratoires publics ou privés. 


\section{Documents de Travail du Centre d'Economie de la Sorbonne}

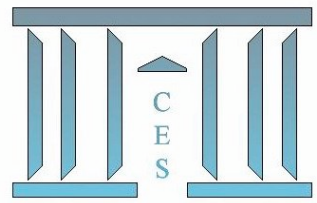

Strategic Communication Networks

Jeanne HAGENBACH, Frédéric KoEsSLER

2009.05

Maison des Sciences Économiques, 106-112 boulevard de L'Hôpital, 75647 Paris Cedex 13 


\title{
Strategic Communication Networks *
}

\author{
Jeanne HagenBACH ${ }^{\dagger} \quad$ Frédéric KOESSLER ${ }^{\ddagger}$
}

February 26, 2009

\footnotetext{
${ }^{*}$ We thank Bruno Biais, Antoni Calvó-Armengol, Ying Chen, Andrew Clark, Olivier Compte, Wouter Dessein, Françoise Forges, Philippe Jehiel, Navin Kartik, David Martimort, Eduardo Perez, Ludovic Renou, Francesco Squintani, Joel Sobel, Jean-Marc Tallon, Jean-Christophe Vergnaud, and seminar participants at Cergy-Pontoise, École Polytechnique, Leicester, Lille, Mannheim, Montpellier, Paris 1, PSE, Strasbourg, Toulouse, University of California at Santa Barbara (Southwest Economic Theory), the second workshop on Strategic Communication and Networks in Valencia and the third world congress of the Game Theory Society in Northwestern for useful comments and discussions.

${ }^{\dagger}$ Université de Paris 1, Centre d'Économie de la Sorbonne, 106-112 Boulevard de l'Hôpital, 75647 Cedex 13, France. E-mail: hagenbach@univ-paris1.fr

${ }^{\ddagger}$ Paris School of Economics and CNRS. E-mail: koessler@pse.ens.fr
} 


\begin{abstract}
We consider situations in which individuals would like to choose an action which is close to that of others, as well as close to a state of nature, with the ideal proximity to the state varying across agents. Before this coordination game is played, a cheap-talk communication stage is offered to the individuals who decide to whom they reveal their private information about the state. The information transmission occurring in the communication stage is characterized by a strategic communication network. We provide an explicit link between players' preferences and the equilibrium strategic communication networks. A key feature of our equilibrium characterization is that whether communication takes place between two agents not only depends on the conflict of interest between these agents, but also on the number and preferences of the other agents with whom they communicate. Apart from some specific cases, the equilibrium communication networks are quite complex despite our simple one-dimensional description of preference heterogeneity. In general, strategic communication networks cannot be completely Pareto-ranked, but expected social welfare always increases as the communication network expands.
\end{abstract}

Résumé : Cet article étudie des situations stratégiques dans lesquelles chaque individu cherche à choisir une action à la fois proche des actions choisies par les autres individus et proche d'un état de la nature, la proximité idéale à cet état variant entre les agents. Avant que ce jeu de coordination soit joué, une étape de communication gratuite est offerte aux individus qui peuvent alors décider à qui ils révèlent les informations privées qu'ils détiennent sur l'état. La transmission d'information qui a lieu au cours de l'étape de communication est caractérisée par un réseau de communication stratégique. Nous caractérisons explicitement les réseaux de communication stratégique qui peuvent émerger à l'équilibre en fonction des préférences des joueurs. Le fait que deux agents communiquent dépend non seulement de leur conflit d'intérêts mais également du nombre et des préférences des autres individus avec lesquels ils communiquent. En dehors de cas spécifiques, les réseaux de communication d'équilibre ont une structure complexe malgré la description uni-dimensionnelle de l'hétérogénéité des préférences. En général, les réseaux de communication stratégique ne peuvent pas être complètement ordonnés au sens de Pareto, mais le bien être social espéré augmente toujours lorsque le réseau de communication s'agrandit.

KEYWORDS: Cheap talk, coordination, incomplete information, networks.

JEL Classification: C72, D82, D83, D85. 


\section{Introduction}

Many economic interactions involve agents who make decisions that are coordinated with those of others, but who have heterogeneous preferences and incomplete information about the appropriate decision. For instance, different privately-informed divisions of an organization have to coordinate their actions to maximize the firm's profit, but each division may be biased in its choice because of career concerns, effort aversion or local adaptation costs. ${ }^{1}$ Similarly, in a market, firms take decisions that are the best suited to the firms' characteristics and the underlying fundamentals, but which may also have a "beauty contest" coordination aspect arising from the strategic complementarities in their actions. Another example is financial analysts who have, first, an interest in making predictions that are similar to those of others and, second, heterogeneous preferences towards such announcements. ${ }^{2}$ Finally, members of a political party are interested in the cohesion of the party, so they advocate the policy that is most in line with that preferred by others and appropriate to the uncertain environment, but at the same time activists may differ in their policy preferences. $^{3}$

In such situations, the objective of this paper is to analyze how agents strategically share the signals they privately hold about the fundamentals. We consider a coordination game with incomplete information in which players can decide to whom they send costless, non-verifiable, and possibly different messages about their private information before taking their payoff-relevant actions. Each player incurs quadratic losses from the mismatch between his one-dimensional action and both others' actions and his own "ideal action". Every player's ideal action depends on the underlying fundamentals and on a systematic positive or negative bias, as in the cheap-talk or delegation models of Crawford and Sobel (1982) and Dessein (2002). These biases vary between individuals, and the profile of biases in the population is a measure of the conflict of interest that agents face. We focus on the way in which players' heterogeneity in ideal actions affects the decentralized and strategic communication between them. We provide a complete characterization of equilibrium communication which roughly boils down to the intuitive statement that agents are more prone to communicate as their ideal actions are closer to each other. For instance, an equilibrium always exists in which players with the same preferences communicate with each other. The same idea is illustrated by the result that, for every agent, strategic communication with agents who are distant in term of their ideal actions also implies strategic communication with agents who are closer in that respect.

Within our stylized framework, we characterize information transmission between players by a strategic communication network, in the sense that a connection is formed from one individual to another if the former truthfully transmits his private information to the latter. We obtain an explicit and tractable result regarding the relationship between players' preference heterogeneity and the equilibrium strategic communication networks, depending on the strength of the coordination motive and the prior information structure. The originality of our approach in modelling communication networks lies in the fact that whether a communication link is formed between two agents is entirely driven by strategic concerns and conflicts of interest between players. That is, players'

\footnotetext{
${ }^{1} \mathrm{~A}$ multi-divisional organization in which decisions must be adapted to local conditions and information but also coordinated between divisions is considered in Alonso, Dessein, and Matouschek (2008) and Rantakari (2008).

${ }^{2}$ Desgranges and Rochon (2007) develop this example.

${ }^{3}$ See, for example, Dewan and Myatt (2008).
} 
benefits from informing or being informed during the communication stage are endogenously determined by the equilibrium outcome of the decision stage. In contrast, in most economic models of non-cooperative network formation, starting with Jackson and Wolinsky (1996), the creation of links is driven by the exogenous costs and benefits of direct and indirect connections between individuals. ${ }^{4}$

Our equilibrium is characterized as follows. A communication network is described by a set of receivers for each player, where a player is said to be a receiver of another player if the latter reveals his private information to the former. Informational incentive constraints require that no player has an interest in lying about his type to his (endogenous) set of receivers. As in standard cheap-talk games (e.g., Crawford and Sobel, 1982), this condition can be formulated as a condition on the proximity between the sender's and receivers' biases, but our incentive constraints are more sophisticated than is typical in such games: a key feature of our model is that the existence of communication between two agents depends not only on the conflict of interest between them, but also on their conflicts of interest regarding the other agents with whom they communicate. First, given our quadratic payoff functions, what matters for the sender's incentive constraint is the average bias of the receivers. It follows that a large bias for one receiver may relax the sender's incentive constraint when the other receivers have a lower bias than the sender. Second, the sender can lie about his type to any subset of receivers. When some of the players in the receiver set have significantly smaller (larger, resp.) bias than the sender, the latter has an incentive to over-report (under-report, resp.) his type to these players only in order to increase (decrease, resp.) their expectations about the state. This in turn increases (decreases, resp.) these receivers' actions, so that the sender can increase (decrease, resp.) his own action which is consequently closer to his ideal point while still coordinated with these receivers' actions. To sum up, our informational incentive constraints require that the sender's bias be close enough to the average bias of every subset of the receiver set.

Lying to a subset of the receivers also creates coordination costs for the sender because the actions of the players he lies to will not be coordinated with those of the other players. This generates what we call a mutual discipline effect of coordination, illustrating that the need for players' actions to be coordinated facilitates information revelation. As the set of receivers of a given sender increases, the incentive constraints with respect to some strict subsets of receivers weaken. Hence, when the informational incentive constraints are satisfied for information transmission to a set of receivers, the same constraints are not necessarily satisfied for information transmission to a strict subset of these receivers. In particular, there may exist an equilibrium in which an individual reveals his type to a group of receivers whereas there is no equilibrium in which he reveals his type to only one member of this group. This also implies that when players are arranged in groups with the same preferences, they tend to communicate more easily to members of other groups as the size of their own group increases.

In general, the structure of the set of equilibrium communication networks is quite complex, and rich insights emerge despite our simple one-dimensional description of preference heterogeneity. One general feature of our model is the multiplicity of equilibrium networks, as is common in communication games, with the additional interesting feature that maximal strategic communication networks are not necessarily unique and cannot be completely Pareto-ranked. That is, there

\footnotetext{
${ }^{4}$ See Jackson (2007) for an extensive survey of such models.
} 
may be an equilibrium in which player 1 transmits his information to players 2 and 3 , another equilibrium in which player 1 transmits his information to players 2 and 4, but no equilibrium in which player 1 transmits his information to players 2, 3 and 4, with player 3 being better off in the first equilibrium and player 4 better off in the second. We show, however, that expected social welfare always rises as the communication network expands, which results when players' conflicts of interests are reduced. Our equilibrium characterization directly provides necessary and sufficient conditions regarding these conflicts for the complete social-welfare maximizing network to be an equilibrium of the communication game.

After characterizing equilibrium communication networks in general, we turn to particular distributions of biases. For example, when biases are uniformly distributed, a player's tendency to communicate always increases with the proximity of his bias to the average bias in the population.

The paper is organized as follows. The model is presented in Section 2, and the welfare comparison of communication networks is carried out in Section 3. Equilibrium communication networks are analyzed in Section 4, and Section 5 focuses on equilibria in which communication is maximal and examines particular distributions of biases. Section 6 concludes and discusses some related literature. Most of the proofs are relegated to the Appendix.

\section{Model}

\subsection{A Class of Coordination Games with Incomplete Information}

Let $N=\{1, \ldots, n\}$ be a finite set of agents, with $n \geq 2$. Each agent chooses an action $a_{i} \in A_{i}=\mathbb{R}$. The action profile is denoted $a=\left(a_{1}, \ldots, a_{n}\right)$. Each agent's payoff depends on the action profile and a state of nature $\theta$. Before the game starts, nobody knows the state of nature, but each agent $i \in N$ receives a private signal $s_{i} \in S_{i}=\left\{\underline{s}_{i}, \bar{s}_{i}\right\}$ about $\theta$, where $\underline{s}_{i}<\bar{s}_{i}$. We assume that agents' types are independent and denote by $q_{i} \in \Delta\left(S_{i}\right)$ the prior probability distribution over agent $i$ 's set of types, for every $i \in N$. When the type profile is $s=\left(s_{1}, \ldots, s_{n}\right)$, the underlying state of nature is $\theta(s) \in \mathbb{R}$.

To obtain explicit and tractable equilibrium characterizations, we assume that the state of nature is additive in types: $\theta(s)=\sum_{i \in N} s_{i} \cdot{ }^{5}$ The difference between the two possible signals of player $i, \bar{s}_{i}-\underline{s}_{i}$, can then be interpreted as the value of private information for player $i$. When this value is relatively high, player $i$ 's private information has a considerable impact on the fundamentals.

Agent $i$ 's payoff function is given by

$$
u_{i}\left(a_{1}, \ldots, a_{n} ; \theta(s)\right)=-(1-\alpha)\left(a_{i}-\theta(s)-b_{i}\right)^{2}-\frac{\alpha}{n-1} \sum_{j \neq i}\left(a_{i}-a_{j}\right)^{2} .
$$

\footnotetext{
${ }^{5}$ This is a standard simplifying assumption in common-value environments, especially in auction theory (see, amongst many others, Bulow and Klemperer, 2002, Mares and Harstad, 2003 and Levin, 2004). Note that the state in our model can be any weighted sum of players' types (since we do not make any assumptions about the two possible values of each signal), and players' signals are not assumed to be i.i.d. (they are only assumed to be independent). The weighted sum of players' private signals is a good approximation of the payoff-relevant state in many situations. In an organizational setting, a signal $s_{i}$ for division $i$ may represent division $i$ 's time, budget or expected benefit from a joint project (which is private information), and the payoff-relevant state that matters for the whole organization may be the total time, budget or expected benefit of the project.
} 
The first component of agent $i$ 's utility function is a quadratic loss in the distance between his action $a_{i}$ and his ideal action $\theta(s)+b_{i}$. The second component is a miscoordination quadratic loss which increases in the average distance between $i$ 's action and other agents' actions. The constant $\alpha \in(0,1)$ weights both sources of quadratic loss, i.e. it parameterizes agents' coordination motives arising from the strategic complementarity in their actions. The constant $b_{i} \in \mathbb{R}$ parameterizes agent $i$ 's preferences over his ideal action in the first component of his utility function. We allow this bias parameter $b_{i}$ to vary across individuals to reflect agents' conflicts of interest with respect to their ideal actions. Were all $b_{i}$ to be equal, there would be no informational incentive problem, and strategic information transmission would therefore be trivial. We assume without loss of generality that players are indexed in increasing order of their biases: $b_{1} \leq \cdots \leq b_{n}$.

The quadratic formulation of players' utility functions, together with the independence of players' types, will allow us to obtain a unique and tractable solution for this Bayesian game whatever the information structure generated by the communication stage (see Subsection 2.3).

\subsection{Communication Game}

Before the coordination game described below is played, but after each player has learnt his type, a communication stage is introduced in which players can send costless and private messages to each other. More precisely, every player $i$ can send a different message $m_{i}^{j} \in M_{i}$ to every other player $j \neq i$, with $M_{i}$ denoting the (non-empty) set of messages available to player $i$. Let $m_{i}=$ $\left(m_{i}^{j}\right)_{j \neq i} \in\left(M_{i}\right)^{n-1}$ be the vector of messages sent by player $i$, and $m^{i}=\left(m_{j}^{i}\right)_{j \neq i} \in \prod_{j \neq i} M_{j} \equiv M_{-i}$ the vector of messages received by player $i$.

In this communication game, player $i$ 's first-stage communication strategy ${ }^{6}$ is a profile $\sigma_{i}=$ $\left(\sigma_{i}^{j}\right)_{j \neq i}$ with

$$
\sigma_{i}^{j}: S_{i} \rightarrow M_{i}
$$

Let $\sigma_{i}^{j}\left(m_{i}^{j} \mid s_{i}\right)$ be the probability ( 0 or 1 ) that player $i$ sends the message $m_{i}^{j}$ to player $j$ according to his strategy $\sigma_{i}$ when his type is $s_{i}$.

Player $i$ 's second-stage decision strategy is a mapping

$$
\tau_{i}: S_{i} \times\left(M_{i}\right)^{n-1} \times M_{-i} \rightarrow A_{i}
$$

where $\tau_{i}\left(s_{i}, m_{i}, m^{i}\right)$ is the action chosen by player $i$ when his type is $s_{i} \in S_{i}$, the vector of private messages $m_{i}=\left(m_{i}^{j}\right)_{j \neq i} \in\left(M_{i}\right)^{n-1}$ was sent, and the vector of private messages $m^{i}=\left(m_{j}^{i}\right)_{j \neq i} \in M_{-i}$ was received. Let $\tau\left(s,\left(m_{i}\right)_{i \in N}\right)=\left(\tau_{i}\left(s_{i}, m_{i}, m^{i}\right)\right)_{i \in N}$ be the corresponding action profile.

A Nash equilibrium ${ }^{7}$ of the communication game is a strategy profile $(\sigma, \tau)=\left(\left(\sigma_{i}\right)_{i \in N},\left(\tau_{i}\right)_{i \in N}\right)$

\footnotetext{
${ }^{6}$ For simplicity, we restrict the analysis to pure-strategy equilibria. While we do not exclude the existence of mixed equilibria, as in the discrete quadratic version of Crawford and Sobel (1982), the full characterization of such equilibria would be quite difficult since we have to consider the possibility that any combination of players randomize over their messages, for any possible combination of receivers. More importantly, the partial transmission of information generated by random strategies would not allow us to identify the equilibrium as a communication network. We would need to instead consider weighted networks, where each link between two players is weighted according to the quantity of information revealed between the two players. For the same tractability reason, we only consider two possible types for each player.

${ }^{7}$ Note that, in our communication game, this definition yields the same equilibrium outcomes as does the perfect Bayesian Nash equilibrium definition.
} 
satisfying the following properties:

(i) For all $i \in N$, and $s_{i} \in S_{i}$,

$$
\left(\sigma_{i}^{j}\left(s_{i}\right)\right)_{j \neq i} \in \arg \max _{m_{i} \in M_{i}^{n-1}} \sum_{s_{-i} \in S_{-i}} q_{-i}\left(s_{-i}\right) u_{i}\left(\tau\left(s,\left(\sigma_{-i}\left(s_{-i}\right), m_{i}\right)\right) ; \theta(s)\right),
$$

where $q_{-i}\left(s_{-i}\right)=\prod_{j \neq i} q_{j}\left(s_{j}\right)$.

(ii) For all $i \in N, m_{i} \in\left(M_{i}\right)^{n-1}$ and $m^{i} \in \operatorname{supp}\left[\sigma_{-i}^{i}\right]$,

$\tau_{i}\left(s_{i}, m_{i}, m^{i}\right) \in \arg \max _{a_{i} \in A_{i}} \sum_{s_{-i} \in S_{-i}} \mu_{i}\left(s_{-i} \mid m^{i}\right) u_{i}\left(\left(\tau_{j}\left(s_{j},\left(\sigma_{j}^{-i}\left(s_{j}\right), m_{j}^{i}\right),\left(\sigma_{-i}^{j}\left(s_{-i}\right), m_{i}^{j}\right)\right)\right)_{j \neq i}, a_{i} ; \theta(s)\right)$,

where $\mu_{i}\left(s_{-i} \mid m^{i}\right)=\prod_{j \neq i} \frac{\sigma_{j}^{i}\left(m_{j}^{i} \mid s_{j}\right) q_{j}\left(s_{j}\right)}{\sum_{t_{j} \in S_{j}} \sigma_{j}^{i}\left(m_{j}^{i} \mid t_{j}\right) q_{j}\left(t_{j}\right)}$.

We will characterize the information-transmission networks that emerge from the cheap-talk extension of the game as (directed) graphs over the set of players. Since we consider only pure strategies and two possible types for each player, any message from player $i$ to player $j$ is either fully revealing or non-revealing, and a communication link is said to be formed from $i$ to $j$ when $i$ 's message to $j$ is fully revealing. Without loss of generality, we consider binary message spaces, $M_{i}=\{\underline{m}, \bar{m}\}$.

Every communication strategy profile $\left(\sigma_{i}\right)_{i \in N}$ can be characterized by a communication network $\left(R_{i}\right)_{i \in N}$, where, for every player $i$,

$$
R_{i} \equiv\left\{j \in N \backslash\{i\}: \sigma_{i}^{j}\left(\underline{s}_{i}\right) \neq \sigma_{i}^{j}\left(\bar{s}_{i}\right)\right\}
$$

is the set of individuals to whom player $i$ reveals his type. Let $r_{i}=\left|R_{i}\right|$ be the number of individuals who learn player $i$ 's type in the communication stage. Using the terminology of graph theory, $R_{i}$ corresponds to player $i$ 's (out)neighborhood and $r_{i}$ to player $i$ 's (out)degree.

\subsection{Second-Stage Equilibrium Characterization}

Given a profile of types $\left(s_{i}\right)_{i \in N}$ and a communication strategy profile characterized by $\left(R_{i}\right)_{i \in N}$, the second-stage equilibrium action of each player $i \in N$ is uniquely given by (see Appendix 7.1)

$$
a_{i}=\sum_{j \in I_{i}} \frac{\alpha\left(n-1-r_{j}\right) E\left(s_{j}\right)+(1-\alpha)(n-1) s_{j}}{n-1-\alpha r_{j}}+\sum_{j \in \bar{I}_{i}} E\left(s_{j}\right)+B_{i},
$$

where $I_{i}=\left\{k: i \in R_{k}\right\} \cup\{i\}$ is the set of signals which are known by player $i$ after the communication stage, $\bar{I}_{i}=\left\{k: i \notin R_{k}\right\} \backslash\{i\}$ is the set of signals which are not known by player $i$ after the communication stage, and

$$
B_{i}=\frac{[(n-1)-(n-2) \alpha] b_{i}+\alpha \sum_{j \neq i} b_{j}}{n+\alpha-1} .
$$

Player $i$ 's optimal action thus has three components. The first is a weighted sum of $j$ 's actual 
type, $s_{j}$, and the expected value of $j$ 's type, $E\left(s_{j}\right)$, for each player $j$ whose type is known by player $i$ (including himself). A greater weight is put on the actual type of player $j$ as the coordination motive, $\alpha$, is lower and as the number of players who know $j$ 's type, $r_{j}$, is higher. This is because a player has a greater incentive to act according to his own private signal when coordination does not matter much and when many other players act according to the same signal. The second component corresponds to the sum of the expected values of $j$ 's type for each player $j$ whose type is not known by player $i$. The last component adjusts the action of player $i$ with respect to the bias profile. This increases in all players' biases, with more weight being put on player $i$ 's own bias, $b_{i}$, as the coordination motive decreases.

The unique and explicit characterization of second-stage equilibrium actions as a function of the information structure and players' preferences enables us to characterize unambiguously, and in a tractable way, the efficient and equilibrium communication strategy profiles, as shown in the following sections.

\section{Efficient Communication Networks}

Before characterizing the equilibrium networks of the communication game, we focus on the efficiency of communication networks. The following proposition compares players' ex ante expected payoffs as the communication network expands, assuming that equilibrium actions are played in the second-stage game. ${ }^{8}$ While an increase in the set of receivers who learn player $i$ 's type is always strictly beneficial for player $i$ and for these receivers, this increase always makes players who do not learn player $i$ 's type strictly worse off. More precisely:

Proposition 1 Consider two communication networks $R=\left(R_{i}, R_{-i}\right)$ and $R^{\prime}=\left(R_{i}^{\prime}, R_{-i}\right)$ such that $R_{i} \subsetneq R_{i}^{\prime}$.

i) Player $i$ is strictly better off, ex-ante, with the communication network $R^{\prime}$ than with the communication network $R$;

ii) Every player $j \in R_{i}^{\prime}$ (with $j \in R_{i}$ or $j \notin R_{i}$ ) is strictly better off, ex-ante, with the communication network $R^{\prime}$ than with the communication network $R$;

iii) Every player $j \in N \backslash\left(\{i\} \cup R_{i}^{\prime}\right)$ is strictly worse off, ex-ante, with the communication network $R^{\prime}$ than with the communication network $R$.

\section{Proof. See Appendix 7.2.}

The intuition of this result is the following. As in Crawford and Sobel (1982), players' biases enter into players' ex ante expected utility in the same way whatever the information structure. Given the quadratic formulation of the payoffs, the information structure affects a player's ex ante expected utility through its effect on the variance of the difference between his own action and the real state, and the variance of the difference between his own action and others' actions. By revealing his type to other players, a player reduces the second variance (without affecting the first). By obtaining information from other players, a player diminishes both variances. On the contrary, the first variance for a player in situation (iii) of Proposition 1, who is excluded from player $i$ 's

\footnotetext{
${ }^{8}$ As in Crawford and Sobel (1982), it is not possible to compare players' expected payoffs at the interim stage.
} 
information flow, remains unchanged but the second variance rises. This explains why this is the only kind of player who is worse off under $R^{\prime}$ than $R$.

The above proposition implies that, in general, communication networks cannot be completely ranked in the sense of Pareto. In particular, defining a communication network $R^{\prime}=\left(R_{i}^{\prime}\right)_{i \in N}$ as more informative than $R=\left(R_{i}\right)_{i \in N}$ if $R_{i} \subseteq R_{i}^{\prime}$ for every $i \in N$ (with at least one strict inclusion), a more-informative communication network does not Pareto dominate, in general, a less-informative communication network. However, using Proposition 1 iteratively, we obtain that the complete communication network $\left(R_{i}=N \backslash\{i\}\right.$ for all $\left.i \in N\right)$ Pareto dominates every other communication network.

The next proposition shows that, even if it can be harmful for some players, the overall socialwelfare effect of enlarging the set of receivers of every player is always positive. Social welfare is defined as the sum of individual utilities: $w(a ; \theta)=\sum_{i \in N} u_{i}(a ; \theta)$.

Proposition 2 If the communication networks $R^{\prime}=\left(R_{i}^{\prime}\right)_{i \in N}$ and $R=\left(R_{i}\right)_{i \in N}$ are such that $r_{i}^{\prime} \geq r_{i}$ for all $i \in N$, with at least one strict inequality, then welfare is always strictly higher, ex ante, with the communication network $R^{\prime}$ than with the communication network $R$.

\section{Proof. See Appendix 7.3.}

In particular, if a communication network $R^{\prime}$ is more informative than $R$, then welfare is strictly higher with $R^{\prime}$ than with $R$.

\section{Equilibrium Communication Networks}

In this section we provide a full characterization of equilibrium communication networks as a function of the parameters of the game, and derive a number of comparative-statics results. We illustrate the characterization with a four-player example and show how our model generates a mutual discipline effect of coordination. Last, the general qualitative features of the equilibrium sets of receivers are described.

\subsection{Full Characterization}

Our main proposition provides a full characterization of the communication networks that arise as equilibrium outcomes of the cheap-talk extension of the game. In short, the proposition states that a player will communicate with a group of players if his taste is not too different from the average taste of every subset of these players. More precisely, there exists an equilibrium network in which player $i$ 's set of receivers is $R_{i} \subseteq N \backslash\{i\}$ if and only if, for every subset of players in $R_{i}$, the average bias of the players in the subset is close enough to player $i$ 's own bias.

Proposition 3 There exists an equilibrium network in which player i's set of receivers is $R_{i} \subseteq$ $N \backslash\{i\}$ iff for all $R_{i}^{\prime} \subseteq R_{i}$ we have

$$
\left|b_{i}-\frac{\sum_{k \in R_{i}^{\prime}} b_{k}}{r_{i}^{\prime}}\right| \leq \frac{(n-1+\alpha)\left(n-1-\alpha r_{i}^{\prime}\right)}{2(n-1)\left(n-1-\alpha r_{i}\right)}\left(\bar{s}_{i}-\underline{s}_{i}\right) .
$$


Proof. See Appendix 7.4.

This characterization reveals a remarkable insight of our model, which will be further analyzed in the following sections: the incentive to communicate to a given receiver not only depends on the conflict of interest between the sender and the receiver, but also on how the sender communicates with the other players. However, each player's equilibrium communication strategies do not depend on other players' actual communication strategies. This second property simplifies our analysis considerably. The intuition is as follows. Consider a strategy profile in which some player (say, player 1 ) reveals his type to players in $R_{1}$, e.g. by sending them the message $\bar{m}$ when his type is $\bar{s}_{1}$ and the message $\underline{m}$ when his type is $\underline{s}_{1}$. This strategy is optimal if, whatever his type, player 1 has no incentive to send an incorrect message to some or all players in $R_{1}$. Assume that player 1's type is $\bar{s}_{1}$ and consider a deviation in which player 1 reveals the incorrect message to all players in $R_{1}$ (the intuition is exactly the same when player 1's type is $\underline{s}_{1}$ or when he deviates only for a subset of the players in $R_{1}$ ). This (unobservable) deviation is not profitable if player 1's expected utility is no higher when he sends message $\underline{m}$ instead of message $\bar{m}$. Player 1's deviation to sending message $\underline{m}$ instead of $\bar{m}$ when his type is $\bar{s}_{1}$ changes player 1's expected utility by changing (i) players' actions in $R_{1}$, from $\bar{a}_{i}$ to $\underline{a}_{i}$, and (ii) player 1 's best reply to the actions of players in $R_{1}$. The change in actions of the players in $R_{1}$ depends on the difference $\left(\bar{s}_{1}-\underline{s}_{1}\right)$ independently of what they learn about others' types, as $\left(\bar{s}_{1}-\underline{s}_{1}\right)$ enters separately into $\bar{a}_{i}-\underline{a}_{i}$. This clearly depends on the (linear and additive) form of second-stage equilibrium actions, which results from the specific utility functions we use. It also depends on the independence of players' types, ${ }^{9}$ and on the additivity of the state. ${ }^{10}$ Consequently, and again because payoffs are quadratic, player 1's best reply to other players' actions and player 1's expected utility are affected by the change in the actions of players in $R_{1}$ independently of indirect communication links. ${ }^{11}$

Remark. Morgan and Stocken (2008) consider a model involving $n$ "experts" (polled constituents) with no action, who send messages about binary types to a policymaker. In their model, the incentive for an expert to reveal truthfully his type depends on the communication strategies of the other experts. While their model and ours are difficult to compare, an important difference concerns the assumptions regarding the information structure. In our model, types are assumed

\footnotetext{
${ }^{9}$ As an extreme example consider the situation in which some player $j \neq 1$ is almost perfectly informed about player 1's type (i.e., $s_{1}$ and $s_{j}$ are strongly correlated). Then, when players in $R_{1}$ know player $j$ 's signal (i.e., there is a communication link between player $j$ and (some) players in $R_{1}$ ), the message of player 1 has only a limited impact on players' actions (and thus, on player 1's expected payoff), while if player $j$ does not reveal his type to players in $R_{1}$, then player 1's signal has a far stronger impact on players' actions in $R_{1}$.

${ }^{10}$ If the types do not enter separately into the state then the effect on players' actions $\bar{a}_{i}-\underline{a}_{i}$, for $i$ in $R_{1}$, would also depend on other players' types (consider, for example, a state $\theta$ that depends in a multiplicative way on players' types). Note however that the independence property does not rely on the fact that each player has only two possible types. Any deviation from a communication strategy over a larger type space would still generate changes in players' actions that do not depend on indirect network connections. Also note that the resolution of the model would be much more difficult by introducing an additional heterogeneity concerning coordination motives $\left(\alpha_{i}\right)_{i \in N}$, although the intuition for the independence property would not be affected.

${ }^{11}$ More precisely, without deviation each term in player 1's expected utility, $V_{1}$, takes the form $E\left(X^{2} \mid s_{1}\right)$, where $X$ depends linearly on players' actions, types and biases. When player 1 deviates, each term in player 1 's expected utility, $V_{1}^{\prime}$, now takes the form $E\left((X+\epsilon)^{2} \mid s_{1}\right)$ where, as noted above, $\epsilon$ only depends on $\left(\bar{s}_{1}-\underline{s}_{1}\right)$ (and the exogenous parameters of the game). In particular, $\epsilon$ does not depend on players' knowledge in $R_{1}$ about players other than player 1 . Hence, the sign of the difference $V_{1}^{\prime}-V_{1}$, which yields our equilibrium condition in Proposition 3 only depends on the terms in the expression $E\left((X+\epsilon)^{2} \mid s_{1}\right)-E\left(X^{2} \mid s_{1}\right)$, and so on terms that take the following form: $\epsilon^{2}+2 \epsilon E\left(X \mid s_{1}\right)$. Finally, $E\left(X \mid s_{1}\right)$ does not depend on indirect connections, since players' expected (best-reply or equilibrium) actions only depend on the expected values of types.
} 
to be independent, and the state is an additive function of the types. In contrast, in Morgan and Stocken (2008), players' signals about the state are independent conditional on the state. As a consequence, the change in the beliefs of the policymaker and the change in his decision depend on the equilibrium communication strategies that are considered.

Thanks to the independence property and to the quadratic form of the payoff functions, informational incentive constraints can be formulated independently for every player as conditions on the proximity between the sender's bias and the receivers' average biases. When a player's bias is close to the average bias of the receivers, lying about his type creates strong miscoordination costs. On the contrary, if the distance between the sender's bias and the average bias of the receivers is substantial, then the sender has an incentive to over-report or under-report his type so that others' actions will be closer to his ideal action. Since the sender can lie about his type to any subset $R_{i}^{\prime}$ of the set $R_{i}$ of receivers, informational incentive constraints also require that the sender's bias be close enough to the average bias of every such subset $R_{i}^{\prime} \subseteq R_{i}$. Exactly how close this should be depends on the RHS of Equation (4) and the size of the subset $R_{i}^{\prime}$. This will be discussed in more detail below.

\subsection{Comparative Statics}

From Proposition 3 it is easy to derive the general effects of the information structure and players' preferences on equilibrium communication networks. More precisely:

Corollary 1 The equilibrium conditions for information transmission from any player $i$ to any set of receivers become weaker as:

(i) The value of private information, $\bar{s}_{i}-\underline{s}_{i}$, increases;

(ii) The weight on coordination motives, $\alpha$, increases;

(iii) All biases are reduced by the same factor: $\left(b_{1}, \ldots, b_{n}\right) \mapsto r\left(b_{1}, \ldots, b_{n}\right)$, where $r \in[0,1)$.

Proof. The RHS of Inequality (4) is clearly increasing in $\bar{s}_{i}-\underline{s}_{i}$. It is also increasing in $\alpha$ because $\frac{\partial}{\partial \alpha} \frac{\left(n-1-\alpha r_{i}^{\prime}\right)}{\left(n-1-\alpha r_{i}\right)}=\frac{(n-1)\left(r_{i}-r_{i}^{\prime}\right)}{\left(n-1-\alpha r_{i}\right)^{2}} \geq 0$. Finally, reducing the absolute values of the biases as in (iii) clearly decreases the LHS of Inequality (4).

The intuition for (ii) and (iii) is quite clear. As the coordination motive increases, or the biases all become closer to each other, the conflict of interest between all players falls, so informational incentive constraints become weaker. The intuition of (i) is also standard. When $\bar{s}_{i}-\underline{s}_{i}$ is small, a player's influence on the receivers' actions is also small so his incentive to lie about his type is greater. In the extreme case in which $\bar{s}_{i}-\underline{s}_{i}$ tends to zero, the incentive constraints of player $i$ would be similar to the condition for full revelation of information in a model with a continuum of types, as in Crawford and Sobel (1982), which is never satisfied except when players' preferences exactly coincide.

The effect of the size of the population, $n$, on communication networks is more difficult to analyze since it is not clear how the profile of biases and the information structure will change when players are added to the population. However, we can first note that, for a given sender and 
a given set of receivers, increasing the total number of players, $n$, strengthens the conditions on the proximity between the sender's and receivers' biases, since the RHS of Equation (4) is decreasing in $n .^{12}$ The intuition of this effect is similar to the intuition of (i) in the previous corollary: as the total number of players rises, the influence of the actions of a fixed set of receivers is smaller, so the sender's incentive to misrepresent his type is greater.

If we consider variations in the size of the population, a more natural form of the model would probably be to describe the state as the average of players' signals, instead of the sum (this is irrelevant when $n$ is fixed, since we impose no restrictions on $\bar{s}_{i}$ and $\underline{s}_{i}$ ). Equivalently, we can replace each signal $s_{i}$ of every player $i$ by $\frac{s_{i}}{n}$. In this case, the RHS of Inequality (4) always tends to zero as $n$ increases, whatever the set of receivers, so that information transmission becomes impossible between any pair of players who do not have the same preferences. This effect is similar to that observed by Morgan and Stocken (2008, Proposition 1) who show that truthful reporting is never an equilibrium for a sufficiently large sample of constituents.

\subsection{A Four-player Example}

As an illustration we consider a game with $n=4$ players, $\alpha=1 / 2$, and assume that every player has the same value of private information, given by $\bar{s}_{i}-\underline{s}_{i}=\frac{12 \times 3}{7}$. The RHS of Equation (4) in Proposition 3 simplifies to $3 \frac{6-r_{i}^{\prime}}{6-r_{i}}$. It follows that player $i$ reveals his type to all of the other players if for all $k, l \in N \backslash\{i\}$,

$$
\left|b_{i}-\frac{\sum_{j \neq i} b_{j}}{3}\right| \leq 3, \quad\left|b_{i}-\frac{b_{k}+b_{l}}{2}\right| \leq 4, \quad \text { and } \quad\left|b_{i}-b_{k}\right| \leq 5 .
$$

Similarly, player $i$ reveals his type only to players in $\{j, k\} \subsetneq N \backslash\{i\}$ if

$$
\left|b_{i}-\frac{b_{j}+b_{k}}{2}\right| \leq 3, \quad \text { and } \quad\left|b_{i}-b_{j}\right|,\left|b_{i}-b_{k}\right| \leq 3.75
$$

Finally, player $i$ reveals his type only to player $j \neq i$ if $\left|b_{i}-b_{j}\right| \leq 3$. For example, with the bias profile $b=\left(b_{1}, b_{2}, b_{3}, b_{4}\right)=(0,3.8,4.8,9),\left(R_{i}\right)_{i \in N}=(\emptyset,\{3\},\{1,2,4\}, \emptyset)$ is the most informative ${ }^{13}$ equilibrium communication network, and is represented in Figure 1.

The informational incentive constraints in this example clearly show that whether communication is feasible from a given sender to a given receiver depends on the whole set of players to whom the sender reveals his information. More precisely, Proposition 3's conditions on the proximity between $i$ 's bias and the average bias of the strict subsets $R_{i}^{\prime} \subsetneq R_{i}$ of receivers become weaker as the set of all receivers, $R_{i}$, increases. This effect, which we call the mutual discipline of coordination, becomes even stronger as $\alpha$ increases. The intuition is that when the set of receivers and the coordination motive become larger, any deviation in the communication stage to a strict subset of the receivers generate higher coordination costs, as this deviation will miscoordinate the actions of players in that strict subset with the other receivers towards whom the sender does not deviate. This effect is absent in the one sender - two receivers model of Farrell and Gibbons (1989), in which

\footnotetext{
${ }^{12}$ The sign of the derivative with respect to $n$ is $2 \alpha(n-1) r_{i}^{\prime}-\alpha^{2} r_{i} r_{i}^{\prime}-(n-1)^{2}\left(r_{i}+1-r_{i}^{\prime}\right)$, which is always negative.

${ }^{13}$ That is, it is more informative than every other equilibrium network. Such an equilibrium does not always exist, as shown in the next section.
} 


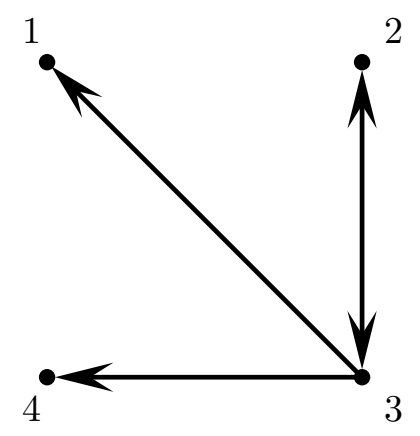

Figure 1: An equilibrium communication network in the Four-player example when $b=$ $(0,3.8,4.8,9)$.

the payoff of each decision-maker only depends on his own action, while in our model players want to coordinate their actions. As an illustration, consider the bias profile $b=(-4.1,0,3.8,4.1)$ in the previous four-player example. There is then an equilibrium in which player 2 reveals his type to all players in $R_{2}=\{1,3,4\}$, but there is no equilibrium in which he reveals his information to any strict subset of $R_{2}$ only.

\subsection{General Features of Equilibrium Sets of Receivers}

Since informational incentive constraints between two agents depend not only on the conflict of interest between these two agents, but also on their conflict of interest with respect to the other agents with whom they communicate, the structure of the set of equilibrium communication networks may be fairly complex. However, by taking a closer look at the way in which the informational incentive constraints given in Proposition 3 intersect, some general features of the equilibrium sets of receivers can be deduced. First, we can always construct larger equilibrium sets of receivers by adding agents whose biases are closer to the sender's bias than to those of any of his receivers.

Corollary 2 If there exists an equilibrium network in which player $i$ 's set of receivers is $R_{i}$, then there also exists an equilibrium network in which player i's set of receivers is $R_{i} \cup\{j\}$ for every player $j$ whose bias is closer to $i$ 's bias than to those of any player in $R_{i}$, i.e.,

$$
\left|b_{i}-b_{j}\right| \leq\left|b_{i}-b_{k}\right|, \quad \forall k \in R_{i} .
$$

\section{Proof. See Appendix 7.5.}

In particular, the above corollary implies that, for every player $i$, there always exists an equilibrium communication network in which his set of receivers $R_{i}$ includes all the players with the same bias $b_{i}$. Note that if condition (7) holds only for some players in $R_{i}$, but not for all of them, then the result may not hold. To see this, consider again the four-player example with the bias profile $b=(0,2.2,3.2,3.7)$. In this case, there is an equilibrium in which player 1 's set of receivers is $R_{1}=\{2,4\}$ but no equilibrium in which it is $\{2,3,4\}$. 
Second, it is obvious from Proposition 3 that the existence of an equilibrium network in which player $i$ 's set of receivers is $\{j\}$, with $j>i$, implies the existence of an equilibrium in which his set of receivers is $\{k\}$, for every $k$ between $i$ and $j$. Applying the previous corollary, this yields:

Corollary 3 If there exists an equilibrium network in which player i's set of receivers is $\{j\}$, then there also exists an equilibrium network in which player $i$ 's set of receivers is $R_{i}$ for every $R_{i} \subseteq\{i+1, \ldots, j\}$.

Proof. Directly from Proposition 3 and Corollary 2.

Note that if players $i$ and $j$ have the same value of private information, i.e. $\bar{s}_{i}-\underline{s}_{i}=\bar{s}_{j}-\underline{s}_{j}$, and if there is an equilibrium network in which player $i$ 's set of receivers is $\{j\}$, then there is also an equilibrium network in which player $j$ 's set of receivers is $\{i\}$. Combined with the previous corollary, this reciprocity property implies that if all players in $\{i, \ldots, j\}$ have the same value of private information, then any communication among these players is possible in equilibrium. In particular, full revelation of information between all of the players in $\{i, \ldots, j\}$ is an equilibrium.

\section{Maximal Equilibrium Communication Networks}

In this section, we focus on maximal equilibrium communication networks. An equilibrium communication network $R$ is said to be maximal if there exists no equilibrium communication network that is more informative than $R$. For instance, the equilibrium communication network in Figure 1 is the unique maximal network in the example as it is more informative than every other equilibrium network. We first provide conditions for the complete, most informative, communication network to be an equilibrium. In the case that it is not, we show how our model can generate a multiplicity of maximal equilibrium networks. Finally, maximal equilibrium networks are analyzed for two particular distributions of biases.

\subsection{The Complete Network}

Obviously, if the complete communication network is an equilibrium, then it is the unique maximal equilibrium network. From the equilibrium characterization of Proposition 3 we directly obtain the necessary and sufficient conditions for this network to be an equilibrium. When all players have the same value of private information, the set of these conditions is reduced, since we only have to check that the incentive constraints are satisfied for the two extreme players (player 1 and player $n$ ). More precisely:

Corollary 4 The complete communication network is an equilibrium network if and only if for all $i \in N$ and $R_{i} \subseteq N \backslash\{i\}$,

$$
\left|b_{i}-\frac{\sum_{j \in R_{i}} b_{j}}{r_{i}}\right| \leq \frac{(n-1+\alpha)\left(n-1-\alpha r_{i}\right)}{2(n-1)^{2}(1-\alpha)}\left(\bar{s}_{i}-\underline{s}_{i}\right) .
$$

When each player has the same value of private information, i.e. $\bar{s}_{i}-\underline{s}_{i}=\bar{s}_{j}-\underline{s}_{j}$ for every $i, j \in N$, the complete communication network is an equilibrium network if and only if these conditions are 
satisfied for $i=1$ and $i=n$.

Proof. Directly from Proposition 3.

Note that a simple sufficient condition for the complete network to be an equilibrium is that there exist an equilibrium network in which player 1's set of receivers is $R_{1}=\{n\}$ and player $n$ 's set of receivers is $R_{n}=\{1\}$.

\subsection{Multiplicity of Maximal Equilibrium Networks}

If larger equilibrium sets of receivers can be constructed by forming the union of existing equilibrium sets, then there would result a unique maximal equilibrium communication network. As stated in the following corollary, combining two equilibrium sets of receivers $R_{i}$ and $\tilde{R}_{i}$ for player $i$ yields an equilibrium set of receivers $R_{i} \cup \tilde{R}_{i}$ for player $i$ if $R_{i}$ and $\tilde{R}_{i}$ do not overlap, i.e. $R_{i} \cap \tilde{R}_{i}=\emptyset$. Hence, in this case, it cannot hold that $R_{i}$ or $\tilde{R}_{i}$ be a set of receivers for player $i$ in a maximal equilibrium network.

Corollary 5 If there is an equilibrium network in which player $i$ 's set of receivers is $R_{i}$, and an equilibrium network in which player $i$ 's set of receivers is $\tilde{R}_{i}$, and if $R_{i}$ and $\tilde{R}_{i}$ do not overlap, then there is also an equilibrium network in which player $i$ 's set of receivers is $R_{i} \cup \tilde{R}_{i}$.

\section{Proof. See Appendix 7.5.}

More generally, the proof of the corollary reveals that a sufficient condition for the result to hold is that the distance between $i$ 's bias and the average bias in $R_{i} \cup \tilde{R}_{i}$ be smaller than the distance between $i$ 's bias and the average bias in $R_{i}$ or $\tilde{R}_{i}$. When this condition does not hold, the union of the two equilibrium receiver sets does not necessarily yield another equilibrium receiver set. To see this, consider once more the four-player example with the bias profile $b=(0,2.2,3.2,3.7)$ from Subsection 4.4. Here, there is an equilibrium network in which player $i=1$ 's set of receivers is $R_{1}=\{2,3\}$ and an equilibrium network in which it is $\tilde{R}_{1}=\{2,4\}$, but no equilibrium network in which player 1's set of receivers is $R_{1} \cup \tilde{R}_{1}=\{2,3,4\}$. This implies that maximal equilibrium networks are not necessarily unique.

\subsection{Information Revelation for Two Particular Distributions of Biases}

We can derive further general results on communication in the maximal networks for two particular distributions of biases. We first consider uniformly-distributed biases, i.e., $b_{i+1}-b_{i}=\beta \geq 0$ for every $i \in N$. From Corollary 1 (iii) we know that in maximal equilibrium networks the number of receivers of every player falls with $\beta$. That is, communication decreases as the distance between all players increases. In addition, we have:

Corollary 6 (Uniformly-Distributed Biases) When players' biases are uniformly distributed and each player has the same value of private information, then in the maximal equilibrium networks the number of receivers of a player increases in the proximity of his bias to the average bias in the population. 
Proof. Directly from Proposition 3 since, for any size $r_{i}$ of receivers, the average distance between $i$ 's bias and the average bias of the $r_{i}$ players who are the closest to $i$ falls with the proximity of $i$ 's bias to the average bias in the population.

We have already noted the tendency of "extremists" (i.e. players whose biases are far from the average bias in the population) to communicate less than do middle-biased players (i.e. players whose biases are close to the average bias in the population) in the second part of Corollary 4 . Indeed, we saw that the full revelation of information between all players is possible whenever the two extreme players reveal their information to all of the other players. With uniformly-distributed biases, a stronger statement can be made, since the previous corollary states that middle-biased players always communicate more than do extremists in the maximal equilibrium networks. In particular, a central player may reveal his information to all players, while an extreme player may transmit his information to no-one.

Finally, we consider a two-spike biases situation in which the players are divided up into two groups, namely $L=\{1, \ldots, l\}$ and $M=\{l+1, \ldots, n\}$. Players in the first group have bias $b_{L}$ and players in the second group have bias $b_{M}$, with $b_{M}-b_{L}=\beta>0$. From Corollary 1 (iii) we know that the number of receivers of every player falls with $\beta$. Corollary 2 also implies that the full revelation of information amongst all players in the same group is always an equilibrium, and that if a player $i \in L\left(i \in M\right.$, resp.) transmits his information to players in $R_{i}$ in equilibrium, then there is also an equilibrium in which $i$ reveals his information to players in $R_{i} \cup(L \backslash\{i\})\left(R_{i} \cup(M \backslash\{i\})\right.$, resp.). Hence, there is a unique maximal equilibrium network, such that the set of receivers of each player $i \in L$ includes all players in $L \backslash\{i\}$ and the set of receivers of each player $i \in M$ includes all players in $M \backslash\{i\}$.

Since it is always possible for players to communicate to players with the same bias, and since informational incentive constraints become weaker as the total number of receivers increases (due to the mutual discipline effect of coordination), it is easy to show that in the maximal equilibrium network a player's informational incentive constraints are relaxed as the relative number of players with the same bias increases. That is, the possible communication links that a player can have with all players increases as the relative number of players close to him (in his group) increases. More precisely:

Corollary 7 (Two-Spike Biases) In the maximal equilibrium network with two-spike biases, a player's set of receivers increases, and includes more players from the other group, as the relative number of players in his own group increases.

Proof. Directly from Proposition 3 and the observations above.

In particular, this corollary implies that intergroup information transmission is higher for players in the larger group than for players in the smaller group when all players have the same value of private information. Unfortunately, this does not extend to more than two groups of players. For example, in the four-player example, when $\alpha=0.9$ and $\bar{s}_{i}-\underline{s}_{i}=1$ for all $i$, the condition for player $i$ to reveal his information to all players is

$$
\left|b_{i}-\frac{\sum_{j \neq i} b_{j}}{3}\right| \leq 0.65, \quad\left|b_{i}-\frac{b_{k}+b_{l}}{2}\right| \leq 2.6, \quad \text { and } \quad\left|b_{i}-b_{k}\right| \leq 4.55
$$


Hence, when $b=(-3,0,0,3)$ there is an equilibrium in which players with zero bias transmit their information to all of the other players, but the first inequality does not hold when $b=(0,0,0,3)$. Actually, when there are more than two groups of players with the same bias, the corollary above only applies, in general, for players in the two extreme groups, i.e., the group with bias $b_{1}$ and that with bias $b_{n}$.

\section{Conclusion}

It is now commonly-admitted that much of the information required for economic decision-making is exchanged in a decentralized way via networks of relationships. However, the literature on networkformation games has not analyzed whether information is effectively transmitted once a link has been formed. In this paper, we focus on agents' incentives to misrepresent their information and derive the equilibrium networks regarding the informativeness of agents' communication strategies. More precisely, we consider a class of economically-relevant coordination games in which information about a common state of nature is distributed between players. These players choose an action by trading off the benefit of it being close to their "ideal action", depending on both the state and an idiosyncratic bias, with that of choosing actions which are close to those of other players. We analyze the way in which preference heterogeneity affects the strategic information transmission that occurs before decisions are taken in this setting. Communication among players is characterized by a strategic communication network in which a connection is formed from one agent to another if the former truthfully reveals his private information to the latter. We provide explicit conditions over the proximity of players' biases for a communication network to be an equilibrium of the cheap-talk extension of the game. The main result is that an agent will reveal his information to a group of agents as long as this group is large enough and his ideal action is close enough to the average ideal action of every subset of agents in this group.

Related Literature. When individuals differ only in terms of knowledge, but not in preferences, the way in which coordination and welfare is affected by the information structure, and in particular by the public or private nature of individuals' signals is theoretically well-established (see, for example, Morris and Shin, 2002 and Angeletos and Pavan, 2007). The most efficient way to disseminate information about fundamentals can therefore be analyzed. When agents' goals are aligned, but there are physical or cost constraints on the number of communication links between agents, another literature has identified the most efficient communication structures. This problem has been analyzed in different settings in team theory and coordination games with incomplete information by, amongst others, Marschak and Radner (1972), Radner (1993), Jehiel (1999), Chwe (2000), Calvó-Armengol and Martí (2007, 2009), and Morris and Shin (2007). A common feature of these papers is that there is no conflict of interest between agents regarding the ideal state-contingent action profile. Consequently, efficient networks are characterized under physical communication constraints, while our approach concerns the equilibrium communication networks that arise under strategic communication constraints.

Since cheap-talk communication is offered to players before they take their decisions, our paper is methodologically related to the literature on strategic information transmission based on Crawford and Sobel (1982). Our model includes multiple and interdependent decision-makers, all of whom 
are endowed with private information, whereas most extensions of Crawford and Sobel's senderreceiver game with more than two players involve multiple senders (with no decision) but only one uninformed receiver. ${ }^{14}$ Exceptions in the literature on cheap talk with multiple receivers (but only one informed sender) are the paper by Farrell and Gibbons (1989) and the economic applications noted by, for example, Levy and Razin (2004). ${ }^{15}$ In Farrell and Gibbons's (1989) framework, the main question addressed is whether it makes a difference whether private or public messages are sent to the receivers. Farrell and Gibbons illustrate a situation, called the mutual discipline of public communication, in which information is revealed to neither decision-maker when communication is private, but a fully-revealing equilibrium is played when communication takes place publicly. Contrary to Farrell and Gibbons (1989), the receivers we consider are not independent decisionmakers whose actions are separable in the sender's utility function. This enables us to identify a mutual discipline effect of coordination which is absent in this literature.

Two recent papers are closely-related to the present work in that they consider incentive conflicts over decisions and therefore endogenize communication between agents. Alonso et al. (2008) and Rantakari (2008) both analyze strategic communication in a two-division organization in which the decisions of the divisions are both responsive to local specificities and coordinated with each other. Decision-makers' payoffs are similar to those we consider, but the conflicts of interest regarding decisions are modeled differently. In Alonso et al. (2008) and Rantakari (2008), each division manager has an ideal action that depends on an idiosyncratic state, and maximizes a weighted sum of his own division's profit and that of the other division. The focus is on determining the best organizational arrangement as a function of these biases and the relative importance of the need for coordination.

\section{Appendix}

\subsection{Second-Stage Equilibrium Characterization}

We first characterize the unique equilibrium action profile under complete information. The utility function of player $i$ (see Equation (1)) can be rewritten as (minus a constant):

$$
a_{i}\left[2(1-\alpha)\left(\theta+b_{i}\right)+\frac{2 \alpha}{n-1} \sum_{j \neq i} a_{j}-a_{i}\right]-\frac{\alpha}{n-1} \sum_{j \neq i}\left(a_{j}\right)^{2} .
$$

The best response of each player $i$ to $a_{-i}$ is given by:

$$
a_{i}\left(a_{-i} ; \theta\right)=(1-\alpha)\left(\theta+b_{i}\right)+\frac{\alpha}{n-1} \sum_{j \neq i} a_{j} .
$$

If $a_{i}$ is a best response to $a_{-i}$, then it follows from Equations (10) and (11) that player $i$ 's utility

\footnotetext{
${ }^{14}$ For example, Battaglini (2002), Krishna and Morgan (2001), Ambrus and Takahashi (2008), and Morgan and Stocken (2008).

${ }^{15}$ Of course, a number of game-theoretical, but more abstract, papers deal with general cheap-talk games, but the focus is mainly on characterizing conditions under which a (mediated) communication equilibrium can be decentralized via multilateral and multistage communication (see the references in Forges, 2007).
} 
takes the following simple form (minus a constant):

$$
u_{i}\left(a_{i}\left(a_{-i} ; \theta\right), a_{-i} ; \theta\right)=\left(a_{i}\left(a_{-i} ; \theta\right)\right)^{2}-\frac{\alpha}{n-1} \sum_{j \neq i}\left(a_{j}\right)^{2} .
$$

The system of equations formed by Equation (11) can be written as:

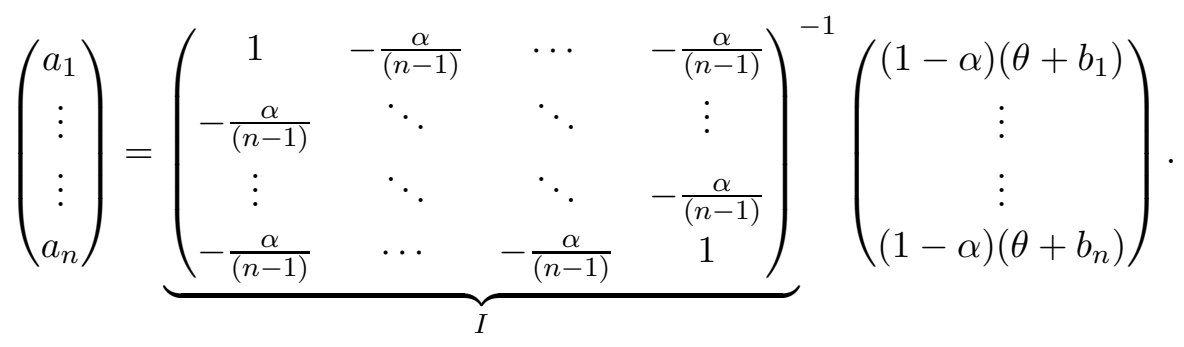

Simple algebra yields:

$$
I^{-1}=\frac{1}{(n-1)-(n-2) \alpha-\alpha^{2}}\left(\begin{array}{cccc}
(n-1)-(n-2) \alpha & \alpha & \cdots & \alpha \\
\alpha & \ddots & \ddots & \vdots \\
\vdots & \ddots & \ddots & \alpha \\
\alpha & \cdots & \alpha & (n-1)-(n-2) \alpha
\end{array}\right) .
$$

Therefore, when every player knows the state of nature, equilibrium actions are given by:

$$
a_{i}(\theta)=\theta+\frac{[(n-1)-(n-2) \alpha] b_{i}+\alpha \sum_{j \neq i} b_{j}}{n+\alpha-1} \equiv \theta+B_{i} \text {, for every } i \in N .
$$

Since players' best responses are linear, exactly the same algebra shows that, under incomplete information, and whatever the information structure generated by the communication strategy profile, expected equilibrium actions are uniquely characterized by

$$
E\left(a_{i}\right)=E(\theta)+B_{i}, \text { for every } i \in N \text {. }
$$

The uniqueness of the linear equilibrium identified in (2) is proved as in Calvó-Armengol and Martí (2009, Theorem 1). We define the following payoff function:

$$
v\left(a_{1}, \ldots, a_{n} ; s\right)=-(1-\alpha) \sum_{i \in N}\left(a_{i}-\theta(s)-b_{i}\right)^{2}-\frac{\alpha}{2(n-1)} \sum_{i \in N} \sum_{j \neq i}\left(a_{i}-a_{j}\right)^{2} .
$$

The set of equilibria of our second-stage coordination game is the same as that in the corresponding Bayesian game with identical agent preferences in which every player's payoff function is given by (15), as the best responses are identical in both games.

Theorem 4 of Marschak and Radner (1972)[167-168] provides a sufficient condition for the equilibrium of a Bayesian game with identical agent preferences to be determined uniquely by a system of linear equations when the set of states of the world is finite and payoff functions are given by: 


$$
\lambda(s)+2 \sum_{i \in N} \mu_{i}(s) a_{i}-\sum_{i, j \in N} v_{i j}(s) a_{i} a_{j},
$$

where the $\lambda, \mu_{i}$ and $v_{i j}$ are all real-valued functions of the state of the world, $s \in S$. It is easily checked that the payoff function (15) can be written as (16), with

$$
\begin{aligned}
& \lambda(s)=-(1-\alpha) \sum_{i \in N}\left(\theta(s)+b_{i}\right)^{2}, \\
& \mu_{i}(s)=(1-\alpha)\left(\theta(s)+b_{i}\right), \\
& v_{i i}(s)=v_{i i}=1 \\
& v_{i j}(s)=v_{i j}=-\frac{\alpha}{n-1} .
\end{aligned}
$$

The sufficient condition in Theorem 4 of Marschak and Radner (1972) then boils down to the $n$-square matrix of cross-derivatives $\left[v_{i j}\right]_{i, j \in N}$ being positive definite. The determinant of $\left[v_{i j}\right]_{i, j \in N}$ is:

$$
\begin{aligned}
& \left|\begin{array}{cccc}
1 & -\frac{\alpha}{n-1} & \cdots & -\frac{\alpha}{n-1} \\
-\frac{\alpha}{n-1} & \ddots & \ddots & \vdots \\
\vdots & \ddots & \ddots & -\frac{\alpha}{n-1} \\
-\frac{\alpha}{n-1} & \cdots & -\frac{\alpha}{n-1} & 1
\end{array}\right|=(1-\alpha)\left|\begin{array}{cccc}
1 & -\frac{\alpha}{n-1} & \cdots & -\frac{\alpha}{n-1} \\
1 & \ddots & \ddots & \vdots \\
\vdots & \ddots & \ddots & -\frac{\alpha}{n-1} \\
1 & \ldots & -\frac{\alpha}{n-1} & 1
\end{array}\right| \\
& =(1-\alpha)\left|\begin{array}{cccc}
1 & -\frac{\alpha}{n-1} & \cdots & -\frac{\alpha}{n-1} \\
0 & 1+\frac{\alpha}{n-1} & 0 & \vdots \\
\vdots & \ddots & \ddots & 0 \\
0 & \cdots & 0 & 1+\frac{\alpha}{n-1}
\end{array}\right|=(1-\alpha)\left(1+\frac{\alpha}{n-1}\right)^{n-1} .
\end{aligned}
$$

The first equality results from the replacement of the elements in the first column by the row sum, and then taking out the common factor $(1-\alpha)$. The second equality is obtained by subtracting the first row from every other row. We are left with an upper triangular matrix whose determinant is just the product of the diagonal term, which is positive. Similarly, we deduce that the leading principal minors of $\left[v_{i j}\right]_{i, j \in N}$ are positive. The matrix $\left[v_{i j}\right]_{i, j \in N}$ is thus positive definite.

Next, by explicitly solving some particular incomplete-information situations as above, it is possible to guess the general form of the unique second-stage equilibrium actions. To check that the solution given by Equation (2) is indeed the equilibrium when the communication strategy profile is characterized by $\left(R_{i}\right)_{i \in N}$, fix some player $l \in N$ and suppose that the second-stage equilibrium action of every player $i \neq l$ is given by Equation (2). We then show that player $l$ 's best response to this profile of second-stage actions $\left(a_{i}\right)_{i \neq l}$ is also of the form of Equation (2).

After the communication stage, for all $i \in N$, recall that $I_{i}=\left\{k: i \in R_{k}\right\} \cup\{i\}$ is the set of players whose signals are known by player $i, \bar{I}_{i}=\left\{k: i \notin R_{k}\right\} \backslash\{i\}$ the set of players whose signals are not known by player $i$, and let $E_{i}(\cdot)=E\left(\cdot \mid\left\{s_{k}: k \in I_{i}\right\}\right)$ be player $i$ 's expectation operator conditional on the set of signals that he knows. 
The expected payoff of player $l$ after the communication stage is as follows:

$$
-(1-\alpha) E_{l}\left[\left(a_{l}-\sum_{j \in N} s_{j}-b_{l}\right)^{2}\right]-\frac{\alpha}{n-1} \sum_{i \neq l} E_{l}\left[\left(a_{l}-a_{i}\right)^{2}\right]
$$

so his best response is given by:

$$
a_{l}=(1-\alpha)\left(\sum_{j \in I_{l}} s_{j}+\sum_{j \in \bar{I}_{l}} E\left(s_{j}\right)+b_{l}\right)+\frac{\alpha}{n-1} \sum_{i \neq l} E_{l}\left(a_{i}\right) .
$$

Using Equation (2) for $i \neq l$, player l's conditional expectation of player $i$ 's action is given by:

$$
\begin{aligned}
E_{l}\left(a_{i}\right)= & \sum_{j \in I_{i}} \frac{\alpha\left(n-1-r_{j}\right) E\left(s_{j}\right)}{n-1-\alpha r_{j}}+\sum_{j \in I_{i} \cap I_{l}} \frac{(1-\alpha)(n-1) s_{j}}{n-1-\alpha r_{j}} \\
& +\sum_{j \in I_{i} \cap \bar{I}_{l}} \frac{(1-\alpha)(n-1) E\left(s_{j}\right)}{n-1-\alpha r_{j}}+\sum_{j \in \bar{I}_{i}} E\left(s_{j}\right)+B_{i} .
\end{aligned}
$$

Summing over all agents other than $l$, we can write:

$$
\begin{aligned}
& \sum_{i \neq l} E_{l}\left(a_{i}\right)= \\
& =\sum_{i \neq l} \sum_{j \in I_{i} \cap I_{l}} \frac{\alpha\left(n-1-r_{j}\right) E\left(s_{j}\right)}{n-1-\alpha r_{j}}+\sum_{i \neq l} \sum_{j \in I_{i} \cap \bar{I}_{l}} \frac{\alpha\left(n-1-r_{j}\right) E\left(s_{j}\right)}{n-1-\alpha r_{j}}+\sum_{i \neq l} \sum_{j \in I_{i} \cap I_{l}} \frac{(1-\alpha)(n-1) s_{j}}{n-1-\alpha r_{j}} \\
& +\sum_{i \neq l} \sum_{j \in I_{i} \cap \bar{I}_{l}} \frac{(1-\alpha)(n-1) E\left(s_{j}\right)}{n-1-\alpha r_{j}}+\sum_{i \neq l} \sum_{j \in \bar{I}_{i} \cap I_{l}} E\left(s_{j}\right)+\sum_{i \neq l} \sum_{j \in \bar{I}_{i} \cap \bar{I}_{l}} E\left(s_{j}\right)+\sum_{i \neq l} B_{i} .
\end{aligned}
$$

Every signal $s_{j}$ known by player $l$ is known by $r_{j}$ players other than $l$ and not known by $n-1-r_{j}$ players different from $l$; every signal $s_{j}$ not known by player $l$ is known by $r_{j}+1$ players other than $l$ and not known by $n-2-r_{j}$ players other than $l$. This enables us to deduce that:

$$
\begin{aligned}
\sum_{i \neq l} E_{l}\left(a_{i}\right)= & \sum_{j \in I_{l}} r_{j} \frac{\alpha\left(n-1-r_{j}\right) E\left(s_{j}\right)}{n-1-\alpha r_{j}}+\sum_{j \in \bar{I}_{l}}\left(r_{j}+1\right) \frac{\alpha\left(n-1-r_{j}\right) E\left(s_{j}\right)}{n-1-\alpha r_{j}} \\
& +\sum_{j \in I_{l}} r_{j} \frac{(1-\alpha)(n-1) s_{j}}{n-1-\alpha r_{j}}+\sum_{j \in \bar{I}_{l}}\left(r_{j}+1\right) \frac{(1-\alpha)(n-1) E\left(s_{j}\right)}{n-1-\alpha r_{j}} \\
& +\sum_{j \in I_{l}}\left(n-1-r_{j}\right) E\left(s_{j}\right)+\sum_{j \in \bar{I}_{l}}\left(n-2-r_{j}\right) E\left(s_{j}\right)+\sum_{i \neq l} B_{i} . \\
= & \sum_{j \in I_{l}} \frac{r_{j}(1-\alpha)(n-1) s_{j}+(n-1)\left(n-1-r_{j}\right) E\left(s_{j}\right)}{n-1-\alpha r_{j}} \\
& +\sum_{j \in \bar{I}_{l}}(n-1) E\left(s_{j}\right)+\sum_{i \neq l} B_{i} .
\end{aligned}
$$


In addition, we have:

$$
\sum_{i \neq l} B_{i}=\frac{\alpha(n-1) b_{l}+(n-1) \sum_{i \neq l} b_{i}}{n+\alpha-1}
$$

Plugging (21) and (20) into (18) and simplifying, we obtain player l's optimal action, which takes exactly the same form as that in Equation (2).

\subsection{Proof of Proposition 1}

The ex ante equilibrium payoff of player $j \in N$ is given by:

$$
\begin{aligned}
U_{j}= & -(1-\alpha) \operatorname{Var}\left(a_{j}-\sum_{i \in N} s_{i}-b_{j}\right)-(1-\alpha)\left[E\left(a_{j}-\sum_{i \in N} s_{i}-b_{j}\right)\right]^{2} \\
& -\frac{\alpha}{n-1} \sum_{m \neq j} \operatorname{Var}\left(a_{j}-a_{m}\right)-\frac{\alpha}{n-1} \sum_{m \neq j}\left[E\left(a_{j}-a_{m}\right)\right]^{2} .
\end{aligned}
$$

It follows from (14) that $E\left(a_{j}\right)=\sum_{i \in N} E\left(s_{i}\right)+B_{j}$, so we have:

$U_{j}=-(1-\alpha) \operatorname{Var}\left(a_{j}-\sum_{i \in N} s_{i}\right)-\frac{\alpha}{n-1} \sum_{m \neq j} \operatorname{Var}\left(a_{j}-a_{m}\right)-(1-\alpha)\left[B_{j}-b_{j}\right]^{2}-\frac{\alpha}{n-1} \sum_{m \neq j}\left[B_{j}-B_{m}\right]^{2}$.

We consider two communication networks $R=\left(R_{k}\right)_{k \in N}$ and $R^{\prime}=\left(R_{k}^{\prime}\right)_{k \in N}$ such that $R_{i} \neq R_{i}^{\prime}$ and $R_{k}=R_{k}^{\prime}$ for all $k \in N \backslash\{i\}$. That is, $R$ and $R^{\prime}$ are identical except that player $i$ has a different set of receivers in $R^{\prime}$. Player $i$ is fixed throughout the analysis. The ex ante equilibrium payoff of every player $j \in N$ with the communication network $R$ ( $R^{\prime}$, resp.) is denoted by $U_{j}$ ( $U_{j}^{\prime}$, resp.). Given the communication network $R\left(R^{\prime}\right.$, resp.), the second-stage equilibrium action of every player $j \in N$ is denoted by $a_{j}\left(a_{j}^{\prime}\right.$, resp.). For all $j \in N$, given a strategic communication network $R$ ( $R^{\prime}$, resp.), let $I_{j}=\left\{k: j \in R_{k}\right\} \cup\{j\}\left(I_{j}^{\prime}=\left\{k: j \in R_{k}^{\prime}\right\} \cup\{j\}\right.$, resp.) denote the set of players whose signals are known by player $j$, and $\bar{I}_{j}=\left\{k: j \notin R_{k}\right\} \backslash\{j\}\left(\bar{I}^{\prime}{ }_{j}=\left\{k: j \notin R_{k}^{\prime}\right\} \backslash\{j\}\right.$, resp.) the set of players whose signals are not known by player $j$.

For every player $j \in N$, we have:

$U_{j}-U_{j}^{\prime}=(1-\alpha)\left(\operatorname{Var}\left(a_{j}^{\prime}-\sum_{i \in N} s_{i}\right)-\operatorname{Var}\left(a_{j}-\sum_{i \in N} s_{i}\right)\right)+\frac{\alpha}{n-1}\left(\sum_{m \neq j} \operatorname{Var}\left(a_{j}^{\prime}-a_{m}^{\prime}\right)-\sum_{m \neq j} \operatorname{Var}\left(a_{j}-a_{m}\right)\right)$.

The second-stage equilibrium action $a_{j}$ given by (2) enables us to write:

$$
\operatorname{Var}\left(a_{j}-\sum_{i \in N} s_{i}\right)=\operatorname{Var}\left(\sum_{l \in I_{j}} \frac{\alpha\left(n-1-r_{l}\right)\left[E\left(s_{l}\right)-s_{l}\right]}{n-1-\alpha r_{l}}+\sum_{l \in \bar{I}_{j}}\left[E\left(s_{l}\right)-s_{l}\right]+B_{j}\right) .
$$


The independence of signals yields:

$$
\begin{aligned}
& \operatorname{Var}\left(a_{j}-\sum_{i \in N} s_{i}\right) \\
& =\sum_{l \in I_{j}} \operatorname{Var}\left(\frac{\alpha\left(n-1-r_{l}\right) s_{l}}{n-1-\alpha r_{l}}\right)+\sum_{l \in \bar{I}_{j}} \operatorname{Var}\left(s_{l}\right)=\sum_{l \in I_{j}}\left(\frac{\alpha\left(n-1-r_{l}\right)}{n-1-\alpha r_{l}}\right)^{2} \operatorname{Var}\left(s_{l}\right)+\sum_{l \in \bar{I}_{j}} \operatorname{Var}\left(s_{l}\right) \\
& =\sum_{l \in I_{j} \backslash\{i\}}\left(\frac{\alpha\left(n-1-r_{l}\right)}{n-1-\alpha r_{l}}\right)^{2} \operatorname{Var}\left(s_{l}\right)+\sum_{l \in \bar{I}_{j} \backslash\{i\}} \operatorname{Var}\left(s_{l}\right)+\mathbf{1}\left[i \in I_{j}\right]\left(\frac{\alpha\left(n-1-r_{i}\right)}{n-1-\alpha r_{i}}\right)^{2} \operatorname{Var}\left(s_{i}\right) \\
& +\mathbf{1}\left[i \in \bar{I}_{j}\right] \operatorname{Var}\left(s_{i}\right),
\end{aligned}
$$

where $\mathbf{1}\left[i \in I_{j}\right]$ is an indicator function that equals 1 when player $j$ knows the signal $s_{i}$, and $\mathbf{1}\left[i \in \bar{I}_{j}\right]$ is an indicator function that equals 1 when player $j$ does not know the signal $s_{i}$. A similar equation holds for $\operatorname{Var}\left(a_{j}^{\prime}-\sum_{i \in N} s_{i}\right)$, when the communication network is $R^{\prime}$.

The two communication networks $R$ and $R^{\prime}$ that we consider are such that $I_{j} \backslash\{i\}=I_{j}^{\prime} \backslash\{i\}$ and $\bar{I}_{j} \backslash\{i\}=\bar{I}^{\prime}{ }_{j} \backslash\{i\}$, so that for all $j \in N$ we have:

$$
\begin{aligned}
& \operatorname{Var}\left(a_{j}^{\prime}-\sum_{i \in N} s_{i}\right)-\operatorname{Var}\left(a_{j}-\sum_{i \in N} s_{i}\right)=\operatorname{Var}\left(s_{i}\right) \\
& {\left[\mathbf{1}\left[i \in I_{j}^{\prime}\right]\left(\frac{\alpha\left(n-1-r_{i}^{\prime}\right)}{n-1-\alpha r_{i}^{\prime}}\right)^{2}+\mathbf{1}\left[i \in \bar{I}_{j}^{\prime}\right]-\mathbf{1}\left[i \in I_{j}\right]\left(\frac{\alpha\left(n-1-r_{i}\right)}{n-1-\alpha r_{i}}\right)^{2}-\mathbf{1}\left[i \in \bar{I}_{j}\right]\right] .}
\end{aligned}
$$

When the communication network is $R$, for all $j \in N$ and $m \neq j$, we have, from (2):

$$
\begin{aligned}
\operatorname{Var}\left(a_{j}-a_{m}\right)= & \sum_{l \in I_{j} \cap \bar{I}_{m}}\left(\frac{(1-\alpha)(n-1)}{n-1-\alpha r_{l}}\right)^{2} \operatorname{Var}\left(s_{l}\right)+\sum_{l \in \bar{I}_{j} \cap I_{m}}\left(\frac{(1-\alpha)(n-1)}{n-1-\alpha r_{l}}\right)^{2} \operatorname{Var}\left(s_{l}\right) \\
= & \sum_{l \in\left(I_{j} \cap \bar{I}_{m}\right) \backslash\{i\}}\left(\frac{(1-\alpha)(n-1)}{n-1-\alpha r_{l}}\right)^{2} \operatorname{Var}\left(s_{l}\right)+\sum_{l \in\left(\bar{I}_{j} \cap I_{m}\right) \backslash\{i\}}\left(\frac{(1-\alpha)(n-1)}{n-1-\alpha r_{l}}\right)^{2} \operatorname{Var}\left(s_{l}\right) \\
& +\left(\frac{(1-\alpha)(n-1)}{n-1-\alpha r_{i}}\right)^{2}\left[\mathbf{1}\left[i \in I_{j} \cap \bar{I}_{m}\right]+\mathbf{1}\left[i \in \bar{I}_{j} \cap I_{m}\right]\right] \operatorname{Var}\left(s_{i}\right) .
\end{aligned}
$$

A similar equation holds for $\operatorname{Var}\left(a_{j}^{\prime}-a_{m}^{\prime}\right)$ when the communication network is $R^{\prime}$.

The two communication networks $R$ and $R^{\prime}$ are such that $\left(I_{j} \cap \bar{I}_{m}\right) \backslash\{i\}=\left(I_{j}^{\prime} \cap{\overline{I^{\prime}}}_{m}\right) \backslash\{i\}$ and $\left(\bar{I}_{j} \cap I_{m}\right) \backslash\{i\}=\left({\overline{I^{\prime}}}_{j} \cap I_{m}^{\prime}\right) \backslash\{i\}$, so for all $j \in N$ and $m \neq j$ we have:

$$
\begin{aligned}
& \operatorname{Var}\left(a_{j}^{\prime}-a_{m}^{\prime}\right)-\operatorname{Var}\left(a_{j}-a_{m}\right) \\
& =((1-\alpha)(n-1))^{2}\left[\frac{\mathbf{1}\left[i \in I_{j}^{\prime} \cap{\overline{I^{\prime}}}_{m}\right]+\mathbf{1}\left[i \in{\overline{I^{\prime}}}_{j} \cap I_{m}^{\prime}\right]}{\left(n-1-\alpha r_{i}^{\prime}\right)^{2}}-\frac{\mathbf{1}\left[i \in I_{j} \cap \bar{I}_{m}\right]+\mathbf{1}\left[i \in \bar{I}_{j} \cap I_{m}\right]}{\left(n-1-\alpha r_{i}\right)^{2}}\right] \operatorname{Var}\left(s_{i}\right) .
\end{aligned}
$$


Plugging (23) and (24) into (22), we obtain: $U_{j}-U_{j}^{\prime}=$

$$
\begin{aligned}
& (1-\alpha)\left[\mathbf{1}\left[i \in I_{j}^{\prime}\right]\left(\frac{\alpha\left(n-1-r_{i}^{\prime}\right)}{n-1-\alpha r_{i}^{\prime}}\right)^{2}+\mathbf{1}\left[i \in \bar{I}_{j}^{\prime}\right]-\mathbf{1}\left[i \in I_{j}\right]\left(\frac{\alpha\left(n-1-r_{i}\right)}{n-1-\alpha r_{i}}\right)^{2}-\mathbf{1}\left[i \in \bar{I}_{j}\right]\right. \\
& \left.+\alpha(1-\alpha)(n-1) \sum_{m \neq j}\left(\frac{\mathbf{1}\left[i \in I_{j}^{\prime} \cap \bar{I}_{m}^{\prime}\right]+\mathbf{1}\left[i \in \bar{I}_{j}^{\prime} \cap I_{m}^{\prime}\right]}{\left(n-1-\alpha r_{i}^{\prime}\right)^{2}}-\frac{\mathbf{1}\left[i \in I_{j} \cap \bar{I}_{m}\right]+\mathbf{1}\left[i \in \bar{I}_{j} \cap I_{m}\right]}{\left(n-1-\alpha r_{i}\right)^{2}}\right)\right] \operatorname{Var}\left(s_{i}\right) .
\end{aligned}
$$

We next focus on the particular case in which $R_{i} \subsetneq R_{i}^{\prime}$ and let $K=R_{i}^{\prime} \backslash R_{i}$ be the set of agents who belong to $R_{i}^{\prime}$ but not to $R_{i}$. The set $K$ is fixed throughout the analysis, and $|K|=k \geq 1$. Let $\left|R_{i}\right|=r_{i}$ and $\left|R_{i}^{\prime}\right|=r_{i}^{\prime}=r_{i}+k$. To evaluate the sign of $U_{j}-U_{j}^{\prime}$, in order to establish who is better off and who is worse off under the different networks, we distinguish four types of players, as below:

- (i) Players who belong both to $R_{i}$ and to $R_{i}^{\prime}$. For every such player $j \in R_{i}=R_{i}^{\prime} \backslash K$, we have $i \in I_{j}$ and $i \in I_{j}^{\prime}$.

- (ii) Players other than player $i$ who belong neither to $R_{i}$ nor to $R_{i}^{\prime}$. For every such player $j \in N \backslash\left(R_{i}^{\prime} \cup\{i\}\right)=N \backslash\left(R_{i} \cup K \cup\{i\}\right)$, we have $i \in \bar{I}_{j}$ and $i \in{\overline{I^{\prime}}}_{j}$.

- (iii) Players who belong to $R_{i}^{\prime}$ but not to $R_{i}$. For every such player $j \in K=R_{i}^{\prime} \backslash R_{i}$, we have $i \in I_{j}^{\prime}$ and $i \in \bar{I}_{j}$.

- (iv) Player $i$, for whom we have $i \in I_{i}$ and $i \in I_{i}^{\prime}$.

(i) For every player $j \in R_{i}=R_{i}^{\prime} \backslash K$, the set of players other than $j$ can be divided into three disjoint sets of players: $\{i\} \cup\left(R_{i}^{\prime} \backslash(K \cup\{j\})\right), N \backslash\left(R_{i}^{\prime} \cup\{i\}\right)$ and $K$. We have:

- for every player $m \in\{i\} \cup\left(R_{i}^{\prime} \backslash(K \cup\{j\})\right), i \in I_{m}$ and $i \in I_{m}^{\prime}$;

- for every player $m \in N \backslash\left(R_{i}^{\prime} \cup\{i\}\right), i \in \bar{I}_{m}$ and $i \in \bar{I}_{m}^{\prime}$, and we have $\left|N \backslash\left(R_{i}^{\prime} \cup\{i\}\right)\right|=$ $n-1-r_{i}^{\prime}=n-1-r_{i}-k$;

- for every player $m \in K, i \in \bar{I}_{m}$ but $i \in I_{m}^{\prime}$.

Since $i \in I_{j}$ and $i \in I_{j}^{\prime}$, Equation (25) simplifies to:

$$
U_{j}-U_{j}^{\prime}=\alpha(1-\alpha)\left(\frac{n-1-r_{i}^{\prime}}{n-1-\alpha r_{i}^{\prime}}-\frac{n-1-r_{i}}{n-1-\alpha r_{i}}\right) \operatorname{Var}\left(s_{i}\right)
$$

Next, using $r_{i}^{\prime}=r_{i}+k$, we obtain $U_{j}-U_{j}^{\prime}=-\left(\frac{\alpha(1-\alpha)^{2}(n-1) k}{\left(n-1-\alpha r_{i}^{\prime}\right)\left(n-1-\alpha r_{i}\right)}\right) \operatorname{Var}\left(s_{i}\right)<0$. Hence, for all $j \in R_{i}^{\prime} \backslash K$, we have $U_{j}<U_{j}^{\prime}$.

(ii) For every player $j \in N \backslash\left(R_{i}^{\prime} \cup\{i\}\right)=N \backslash\left(R_{i} \cup K \cup\{i\}\right)$, the set of players other than $j$ can be divided into three disjoint sets of players: $\{i\} \cup\left(R_{i}^{\prime} \backslash K\right), N \backslash\left(R_{i}^{\prime} \cup\{i, j\}\right)$ and $K$. We have: 
- for every player $m \in\{i\} \cup\left(R_{i}^{\prime} \backslash K\right), i \in I_{m}$ and $i \in I_{m}^{\prime}$, and we have $\left|\{i\} \cup\left(R_{i}^{\prime} \backslash K\right)\right|=r_{i}+1=$ $r_{i}^{\prime}-k+1$

- for every player $m \in N \backslash\left(R_{i}^{\prime} \cup\{i, j\}\right), i \in \bar{I}_{m}$ and $i \in{\overline{I^{\prime}}}_{m}$;

- for every player $m \in K, i \in \bar{I}_{m}$ but $i \in I_{m}^{\prime}$.

Since $i \in \bar{I}_{j}$ and $i \in{\overline{I^{\prime}}}_{j}$, Equation (25) simplifies to:

$$
U_{j}-U_{j}^{\prime}=\alpha(1-\alpha)^{2}(n-1)\left(\frac{r_{i}^{\prime}+1}{\left(n-1-\alpha r_{i}^{\prime}\right)^{2}}-\frac{r_{i}+1}{\left(n-1-\alpha r_{i}\right)^{2}}\right) \operatorname{Var}\left(s_{i}\right) .
$$

Since $r_{i}^{\prime}>r_{i}$, we have $\left[\frac{r_{i}^{\prime}+1}{\left(n-1-\alpha r_{i}^{\prime}\right)^{2}}-\frac{r_{i}+1}{\left(n-1-\alpha r_{i}\right)^{2}}\right]>0$. Hence, for all $j \in N \backslash\left(R_{i}^{\prime} \cup\{i\}\right)$, we have $U_{j}>U_{j}^{\prime}$.

(iii) For every player $j \in K=R_{i}^{\prime} \backslash R_{i}$, the set of players other than $j$ can be divided into three disjoint sets of players: $\{i\} \cup\left(R_{i}^{\prime} \backslash K\right), N \backslash\left(R_{i}^{\prime} \cup\{i\}\right)$ and $K \backslash\{j\}$. We have:

- for every player $m \in\{i\} \cup\left(R_{i}^{\prime} \backslash K\right), i \in I_{m}$ and $i \in I_{m}^{\prime}$, and we have $\left|\{i\} \cup\left(R_{i}^{\prime} \backslash K\right)\right|=r_{i}+1$;

- for every player $m \in N \backslash\left(R_{i}^{\prime} \cup\{i\}\right), i \in \bar{I}_{m}$ and $i \in{\overline{I^{\prime}}}_{m}$, and we have $\left|N \backslash\left(R_{i}^{\prime} \cup\{i\}\right)\right|=n-1-r_{i}^{\prime}$;

- for every player $m \in K \backslash\{j\}, i \in \bar{I}_{m}$ but $i \in I_{m}^{\prime}$.

Since $i \in \bar{I}_{j}$ and $i \in I_{j}^{\prime}$, Equation (25) simplifies to:

$$
U_{j}-U_{j}^{\prime}=-(1-\alpha)^{2}(n-1)\left(\frac{1}{n-1-\alpha r_{i}^{\prime}}+\frac{\alpha\left(r_{i}+1\right)}{\left(n-1-\alpha r_{i}\right)^{2}}\right) \operatorname{Var}\left(s_{i}\right)<0 .
$$

Hence, for all player $j \in K$, we have $U_{j}<U_{j}^{\prime}$.

(iv) The set of players other than $i$ can be divided into three disjoint sets of players: $R_{i}^{\prime} \backslash K$, $N \backslash\left(R_{i}^{\prime} \cup\{i\}\right)$ and $K$. We have:

- for every player $m \in R_{i}^{\prime} \backslash K, i \in I_{m}$ and $i \in I_{m}^{\prime}$;

- for every player $m \in N \backslash\left(R_{i}^{\prime} \cup\{i\}\right), i \in \bar{I}_{m}$ and $i \in{\overline{I^{\prime}}}_{m}$;

- for every player $m \in K, i \in \bar{I}_{m}$ but $i \in I_{m}^{\prime}$.

Since $i \in I_{i}$ and $i \in I_{i}^{\prime}$, Equation (25) yields exactly the same difference as Equation (26). Hence, for player $i$ such that $R_{i} \subsetneq R_{i}^{\prime}$, we have $U_{i}<U_{i}^{\prime}$. This completes the proof of Proposition 1 .

\subsection{Proof of Proposition 2}

Consider two communication networks $R=\left(R_{i}, R_{-i}\right)$ and $R^{\prime}=\left(R_{i}^{\prime}, R_{-i}\right)$, such that $r_{i}^{\prime}>r_{i}$ and $\left|R_{i} \cap R_{i}^{\prime}\right|=r$. Ex ante expected welfare is the sum of ex ante expected utilities. When the 
communication network is $R^{\prime}$, expected welfare is given by:

$$
W^{\prime}=\sum_{j \in R_{i}^{\prime}} U_{j}^{\prime}+\sum_{j \in N \backslash\left(R_{i}^{\prime} \cup\{i\}\right)} U_{j}^{\prime}+U_{i}^{\prime} .
$$

When the communication network is $R$, it is given by:

$$
W=\sum_{j \in R_{i}} U_{j}+\sum_{j \in N \backslash\left(R_{i} \cup\{i\}\right)} U_{j}+U_{i} .
$$

Using the fact that the set of players $N$ can be divided into five disjoint sets $\{i\}, R_{i} \cap R_{i}^{\prime}, N \backslash\left(R_{i} \cup\right.$ $\left.R_{i}^{\prime} \cup\{i\}\right), R_{i}^{\prime} \backslash R_{i}$ and $R_{i} \backslash R_{i}^{\prime}$, and that for all $j \in\left(R_{i} \cap R_{i}^{\prime}\right), U_{j}-U_{j}^{\prime}=U_{i}-U_{i}^{\prime}$, the difference $W-W^{\prime}$ can be written as:

$W-W^{\prime}=\sum_{j \in\{i\} \cup\left(R_{i} \cap R_{i}\right)}\left[U_{j}-U_{j}^{\prime}\right]+\sum_{j \in N \backslash\left(R_{i} \cup R_{i}^{\prime} \cup\{i\}\right)}\left[U_{j}-U_{j}^{\prime}\right]+\sum_{j \in R_{i}^{\prime} \backslash R_{i}}\left[U_{j}-U_{j}^{\prime}\right]+\sum_{j \in R_{i} \backslash R_{i}^{\prime}}\left[U_{j}-U_{j}^{\prime}\right]$.

We have $\left|\{i\} \cup\left(R_{i} \cap R_{i}^{\prime}\right)\right|=r+1,\left|R_{i}^{\prime} \backslash R_{i}\right|=r_{i}^{\prime}-r,\left|R_{i} \backslash R_{i}^{\prime}\right|=r_{i}-r$ and $\left|N \backslash\left(R_{i} \cup R_{i}^{\prime} \cup\{i\}\right)\right|=$ $n-\left(1+r_{i}+r_{i}^{\prime}-r\right)$. Next, using Equation (25) in the same way as in the proof of Proposition 1, we obtain:

$$
\begin{aligned}
W-W^{\prime}= & \alpha(1-\alpha)(r+1)\left[\frac{n-1-r_{i}^{\prime}}{n-1-\alpha r_{i}^{\prime}}-\frac{n-1-r_{i}}{n-1-\alpha r_{i}}\right] \operatorname{Var}\left(s_{i}\right) \\
& +\alpha(1-\alpha)^{2}(n-1)\left(n-1-r_{i}-r_{i}^{\prime}+r\right)\left[\frac{r_{i}^{\prime}+1}{\left(n-1-\alpha r_{i}^{\prime}\right)^{2}}-\frac{r_{i}+1}{\left(n-1-\alpha r_{i}\right)^{2}}\right] \operatorname{Var}\left(s_{i}\right) \\
& -(1-\alpha)^{2}(n-1)\left(r_{i}^{\prime}-r\right)\left[\frac{1}{n-1-\alpha r_{i}^{\prime}}+\frac{\alpha\left(r_{i}+1\right)}{\left(n-1-\alpha r_{i}\right)^{2}}\right] \operatorname{Var}\left(s_{i}\right) \\
& +(1-\alpha)^{2}(n-1)\left(r_{i}-r\right)\left[\frac{1}{n-1-\alpha r_{i}}+\frac{\alpha\left(r_{i}^{\prime}+1\right)}{\left(n-1-\alpha r_{i}^{\prime}\right)^{2}}\right] \operatorname{Var}\left(s_{i}\right) .
\end{aligned}
$$

After some simplification, we have $W-W^{\prime}=$

$\underbrace{-\frac{(1-\alpha)^{3}(n-1)^{2} \operatorname{Var}\left(s_{i}\right)}{\left(n-1-\alpha r_{i}^{\prime}\right)^{2}\left(n-1-\alpha r_{i}\right)^{2}}}_{<0} \underbrace{\left[\alpha^{2}\left(r_{i}^{2}\left(1+r_{i}^{\prime}\right)-r_{i}^{\prime 2}\left(1+r_{i}\right)\right)+2 \alpha(n-1)\left(r_{i}^{\prime}-r_{i}\right)+(n-1)^{2}\left(r_{i}^{\prime}-r_{i}\right)\right]}_{x}$.

Solving $x=0$ in $\alpha$ yields the following discriminant: $4(n-1)^{2}\left(r_{i}^{\prime}-r_{i}\right)^{2}\left(1+r_{i}\right)\left(1+r_{i}^{\prime}\right) \geq 0$. We have $x \geq 0$ if and only if $\alpha \in\left[\alpha_{1}, \alpha_{2}\right]$, with $\alpha_{1}=\frac{(n-1)\left[1-\sqrt{\left(1+r_{i}\right)\left(1+r_{i}^{\prime}\right)}\right]}{\left(1+r_{i}\right)\left(1+r_{i}^{\prime}\right)-1}$ and $\alpha_{2}=\frac{(n-1)\left[1+\sqrt{\left(1+r_{i}\right)\left(1+r_{i}^{\prime}\right)}\right]}{\left(1+r_{i}\right)\left(1+r_{i}^{\prime}\right)-1}$. From $r_{i} \geq 1$ and $r_{i}^{\prime} \geq 2$, we deduce that $\alpha_{1}<0$. From $r_{i} \leq n-2$ and $r_{i}^{\prime} \leq n-1$, and the fact that $\alpha_{2}$ is decreasing in $r_{i}$ and $r_{i}^{\prime}$, we deduce that $\alpha_{2}>1$. Since $\alpha \in(0,1), x$ is always strictly positive. Hence, $W<W^{\prime}$. 


\subsection{Proof of Proposition 3}

Consider an equilibrium of the private-communication game in which each player $i$ reveals his type to players in $R_{i} \subseteq N \backslash\{i\}$. Without loss of generality, assume that each player $i$ sends to every player $j \in R_{i}$ the message $m_{i}^{j}=\bar{m}$ when his type is $\bar{s}_{i}$ and the message $m_{i}^{j}=\underline{m}$ when his type is $\underline{s}_{i}$, and sends the same message whatever his type to players outside $R_{i}$. Given $\left(R_{i}\right)_{i \in N}$, the second-stage equilibrium actions are given by (2).

Without loss of generality, we look for the conditions under which player 1 does not deviate from his equilibrium communication strategy described above. First, assume that player 1's true type is $s_{1}=\bar{s}_{1}$. In equilibrium, using Equation (2), the second-stage action of every player $i \in R_{1} \cup\{1\}$ is given by

$$
\begin{aligned}
\bar{a}_{i}= & \sum_{j \in I_{i} \backslash\{1\}} \frac{\alpha\left(n-1-r_{j}\right) E\left(s_{j}\right)+(1-\alpha)(n-1) s_{j}}{n-1-\alpha r_{j}}+\sum_{j \in \bar{I}_{i}} E\left(s_{j}\right)+B_{i} \\
& +\frac{\alpha\left(n-1-r_{1}\right) E\left(s_{1}\right)+(1-\alpha)(n-1) \bar{s}_{1}}{n-1-\alpha r_{1}}
\end{aligned}
$$

and the second-stage action of every player $i \notin R_{1} \cup\{1\}$ is given by

$$
a_{i}=\sum_{j \in I_{i}} \frac{\alpha\left(n-1-r_{j}\right) E\left(s_{j}\right)+(1-\alpha)(n-1) s_{j}}{n-1-\alpha r_{j}}+\sum_{j \in \bar{I}_{i} \backslash\{1\}} E\left(s_{j}\right)+B_{i}+E\left(s_{1}\right) .
$$

The relevant deviations for player 1 in the communication stage consist in lying to a subset of players $M \subseteq R_{1}$, i.e. sending message $\underline{m}$ instead of $\bar{m}$ to players in $M$ (and not deviating towards the other players). ${ }^{16}$ Let $m=|M|$, and denote by $\left(a_{i}^{\prime}\right)_{i \in N}$ the profile of players' actions after this deviation. Every player $i \in M$ chooses action $a_{i}^{\prime}=\underline{a}_{i}$, which is given by replacing $\bar{s}_{1}$ by $\underline{s}_{1}$ in (29). The action $a_{i}^{\prime}$ of every player $i \in N \backslash(M \cup\{1\})$ is the same as that in the original equilibrium. Player 1's optimal action in the second stage is obtained from the best response of Equation (18) to $\left(a_{i}^{\prime}\right)_{i \neq 1}$, and takes the following form:

$$
a_{1}^{\prime}=(1-\alpha)\left(\sum_{j \in I_{1} \backslash\{1\}} s_{j}+\bar{s}_{1}+\sum_{j \in \bar{I}_{1}} E\left(s_{j}\right)+b_{1}\right)+\frac{\alpha}{n-1} \sum_{i \neq 1} E_{1}\left(a_{i}^{\prime}\right) .
$$

\footnotetext{
${ }^{16}$ In equilibrium, any message off of the equilibrium path is interpreted as exactly $\underline{m}$ or $\bar{m}$.
} 
Using the same reasoning as that used to obtain expression (20), we have:

$$
\begin{aligned}
\sum_{i \neq 1} E_{1}\left(a_{i}^{\prime}\right)= & \sum_{j \in I_{1}} r_{j} \frac{\alpha\left(n-1-r_{j}\right) E\left(s_{j}\right)}{n-1-\alpha r_{j}}+\sum_{j \in \bar{I}_{1}}\left(r_{j}+1\right) \frac{\alpha\left(n-1-r_{j}\right) E\left(s_{j}\right)}{n-1-\alpha r_{j}} \\
& +\sum_{j \in I_{1} \backslash\{1\}} r_{j} \frac{(1-\alpha)(n-1) s_{j}}{n-1-\alpha r_{j}}+\frac{m(1-\alpha)(n-1) \underline{s}_{1}}{n-1-\alpha r_{1}} \\
& +\frac{\left(r_{1}-m\right)(1-\alpha)(n-1) \bar{s}_{1}}{n-1-\alpha r_{1}}+\sum_{j \in \bar{I}_{1}}\left(r_{j}+1\right) \frac{(1-\alpha)(n-1) E\left(s_{j}\right)}{n-1-\alpha r_{j}} \\
& +\sum_{j \in I_{1}}\left(n-1-r_{j}\right) E\left(s_{j}\right)+\sum_{j \in \bar{I}_{1}}\left(n-2-r_{j}\right) E\left(s_{j}\right)+\sum_{i \neq 1} B_{i} .
\end{aligned}
$$

Plugging (32) into (31), using (21) and simplifying, we obtain:

$$
\begin{aligned}
a_{1}^{\prime}= & \sum_{j \in I_{1} \backslash\{1\}} \frac{\alpha\left(n-1-r_{j}\right) E\left(s_{j}\right)+(1-\alpha)(n-1) s_{j}}{n-1-\alpha r_{j}}+\sum_{j \in \bar{I}_{1}} E\left(s_{j}\right) \\
& +\frac{\alpha m(1-\alpha) \underline{s}_{1}+(n-1-\alpha m)(1-\alpha) \bar{s}_{1}+\alpha\left(n-1-r_{1}\right) E\left(s_{1}\right)}{n-1-\alpha r_{1}}+B_{1} .
\end{aligned}
$$

We denote by $V_{1}$ the expected payoff of player 1 conditional on signal $s_{1}$ under the original equilibrium, and by $V_{1}^{\prime}$ his expected payoff conditional on signal $s_{1}$ when he deviates by lying to players in $M$ (and thus plays action $a_{1}^{\prime}$ in the second-stage game). Player 1 does not deviate by lying to players in $M$ if $V_{1}^{\prime}-V_{1} \leq 0$. We have:

$$
\begin{aligned}
& V_{1}^{\prime}-V_{1}=(1-\alpha) E\left[\left(\bar{a}_{1}-\sum_{i \in N} s_{i}-b_{1}\right)^{2}-\left(a_{1}^{\prime}-\sum_{i \in N} s_{i}-b_{1}\right)^{2} \mid s_{1}\right] \\
& +\frac{\alpha}{n-1}\left(\sum_{i \in M} E\left[\left(\bar{a}_{1}-\bar{a}_{i}\right)^{2}-\left(a_{1}^{\prime}-\underline{a}_{i}\right)^{2} \mid s_{1}\right]\right. \\
& \left.+\sum_{i \in R_{1} \backslash M} E\left[\left(\bar{a}_{1}-\bar{a}_{i}\right)^{2}-\left(a_{1}^{\prime}-\bar{a}_{i}\right)^{2} \mid s_{1}\right]+\sum_{i \in N \backslash\left(R_{1} \cup\{1\}\right)} E\left[\left(\bar{a}_{1}-a_{i}\right)^{2}-\left(a_{1}^{\prime}-a_{i}\right)^{2} \mid s_{1}\right]\right) .
\end{aligned}
$$

For the sake of simplicity, we examine separately the elements of the difference $V_{1}^{\prime}-V_{1}$ and use the following notation for $i \neq 1$ :

$$
z_{i}=\sum_{j \in\left(I_{1} \cap \bar{I}_{i}\right) \backslash\{1\}} \frac{(1-\alpha)(n-1)\left(s_{j}-E\left(s_{j}\right)\right)}{n-1-\alpha r_{j}}+\sum_{j \in\left(\bar{I}_{1} \cap I_{i}\right) \backslash\{1\}} \frac{(1-\alpha)(n-1)\left(E\left(s_{j}\right)-s_{j}\right)}{n-1-\alpha r_{j}}+B_{1}-B_{i} .
$$

Using (29), (30) and (33) and the fact that $E\left[z_{i} \mid s_{1}\right]=B_{1}-B_{i}$ :

$$
\begin{aligned}
& \sum_{i \in M} E\left[\left(\bar{a}_{1}-\bar{a}_{i}\right)^{2}-\left(a_{1}^{\prime}-\underline{a}_{i}\right)^{2} \mid s_{1}\right]=\sum_{i \in M} E\left[z_{i}^{2}-\left(z_{i}+\frac{(1-\alpha)(n-1-\alpha m)\left(\bar{s}_{1}-\underline{s}_{1}\right)}{n-1-\alpha r_{1}}\right)^{2} \mid s_{1}\right] \\
& =-2\left(\frac{(1-\alpha)(n-1-\alpha m)\left(\bar{s}_{1}-\underline{s}_{1}\right)}{n-1-\alpha r_{1}}\right) \sum_{i \in M}\left(B_{1}-B_{i}\right)-m\left(\frac{(1-\alpha)(n-1-\alpha m)\left(\bar{s}_{1}-\underline{s}_{1}\right)}{n-1-\alpha r_{1}}\right)^{2} .
\end{aligned}
$$




$$
\begin{aligned}
& \sum_{i \in R_{1} \backslash M} E\left[\left(\bar{a}_{1}-\bar{a}_{i}\right)^{2}-\left(a_{1}^{\prime}-\bar{a}_{i}\right)^{2} \mid s_{1}\right]=\sum_{i \in R_{1} \backslash M} E\left[z_{i}^{2}-\left(z_{i}-\frac{(1-\alpha) \alpha m\left(\bar{s}_{1}-\underline{s}_{1}\right)}{n-1-\alpha r_{1}}\right)^{2} \mid s_{1}\right] \\
& =2\left(\frac{(1-\alpha) \alpha m\left(\bar{s}_{1}-\underline{s}_{1}\right)}{n-1-\alpha r_{1}}\right) \sum_{i \in R_{1} \backslash M}\left(B_{1}-B_{i}\right)-\left(r_{1}-m\right)\left(\frac{(1-\alpha) \alpha m\left(\bar{s}_{1}-\underline{s}_{1}\right)}{n-1-\alpha r_{1}}\right)^{2} \cdot \quad(35) \\
& \quad \sum_{i \in N \backslash\left(R_{1} \cup\{1\}\right)} E\left[\left(\bar{a}_{1}-a_{i}\right)^{2}-\left(a_{1}^{\prime}-a_{i}\right)^{2} \mid s_{1}\right]=\sum_{i \in N \backslash\left(R_{1} \cup\{1\}\right)} E\left[\left(z_{i}+\frac{(1-\alpha)(n-1)\left(\bar{s}_{1}-E\left(s_{1}\right)\right)}{n-1-\alpha r_{1}}\right)^{2}\right. \\
& \left.-\left(z_{i}+\frac{(1-\alpha) \alpha m \underline{s}_{1}+(1-\alpha)(n-1-\alpha m) \bar{s}_{1}-(1-\alpha)(n-1) E\left(s_{1}\right)}{n-1-\alpha r_{1}}\right)^{2} \mid s_{1}\right] \\
& =2\left(\frac{(1-\alpha) \alpha m\left(\bar{s}_{1}-\underline{s}_{1}\right)}{n-1-\alpha r_{1}} \sum_{i \in N \backslash\left(R_{1} \cup\{1\}\right)}\left(B_{1}-B_{i}\right)+\left(n-1-r_{1}\right)\left(\frac{(1-\alpha)(n-1)\left(\bar{s}_{1}-E\left(s_{1}\right)\right)}{n-1-\alpha r_{1}}\right)^{2}\right. \\
& -\left(n-1-r_{1}\right)\left(\frac{(1-\alpha) \alpha m \underline{s}_{1}+(1-\alpha)(n-1-\alpha m) \bar{s}_{1}-(1-\alpha)(n-1) E\left(s_{1}\right)}{n-1-\alpha r_{1}}\right)^{2} .
\end{aligned}
$$

In addition, using

$$
\bar{a}_{1}-a_{1}^{\prime}=\frac{(1-\alpha) \alpha m\left(\bar{s}_{1}-\underline{s}_{1}\right)}{n-1-\alpha r_{1}}
$$

and

$$
\begin{aligned}
& \bar{a}_{1}^{2}-a_{1}^{\prime 2}=\left(\frac{\alpha\left(n-r_{1}-1\right) E\left(s_{1}\right)+(1-\alpha)(n-1) \bar{s}_{1}}{n-1-\alpha r_{l}}\right)^{2} \\
& -\left(\frac{\alpha m(1-\alpha) \underline{s}_{1}+(n-1-\alpha m)(1-\alpha) \bar{s}_{1}+\alpha\left(n-r_{1}-1\right) E\left(s_{1}\right)}{n-1-\alpha r_{1}}\right)^{2} \\
& +2\left(\sum_{j \in I_{1} \backslash\{1\}} \frac{\alpha\left(n-r_{j}-1\right) E\left(s_{j}\right)+(1-\alpha)(n-1) s_{j}}{n-1-\alpha r_{j}}+\sum_{j \in \bar{I}_{1}} E\left(s_{j}\right)+B_{1}\right)\left(\frac{(1-\alpha) \alpha m\left(\bar{s}_{1}-\underline{s}_{1}\right)}{n-1-r_{1}}\right),
\end{aligned}
$$

we obtain:

$$
\begin{aligned}
& E\left[\left(\bar{a}_{1}-\sum_{i \in N} s_{i}-b_{1}\right)^{2}-\left(a_{1}^{\prime}-\sum_{i \in N} s_{i}-b_{1}\right)^{2} \mid s_{1}\right] \\
& =E\left[\bar{a}_{1}^{2}-a_{1}^{\prime 2} \mid s_{1}\right]-2 E\left[\left(\bar{a}_{1}-a_{1}^{\prime}\right)\left(\sum_{i \in N \backslash\{1\}} s_{i}+s_{1}+b_{1}\right) \mid s_{1}\right] \\
& =\left(\frac{\alpha\left(n-r_{1}-1\right) E\left(s_{1}\right)+(1-\alpha)(n-1) \bar{s}_{1}}{n-1-\alpha r_{1}}\right)^{2}+2\left(B_{1}-b_{1}-\bar{s}_{1}\right)\left(\frac{(1-\alpha) \alpha m\left(\bar{s}_{1}-\underline{s}_{1}\right)}{n-1-\alpha r_{1}}\right) \\
& -\left(\frac{\alpha m(1-\alpha) \underline{s}_{1}+(n-1-\alpha m)(1-\alpha) \bar{s}_{1}+\alpha\left(n-r_{1}-1\right) E\left(s_{1}\right)}{n-1-\alpha r_{1}}\right)^{2} .
\end{aligned}
$$

Next, we plug (34), (35), (36) and (37) into $V_{1}^{\prime}-V_{1}$ and simplify. To simplify the part of the 
difference $V_{1}^{\prime}-V_{1}$ that deals with biases, note that:

$$
B_{1}-B_{i}=\frac{(1-\alpha)(n-1)\left(b_{1}-b_{i}\right)}{n+\alpha-1} \text { and } B_{1}-b_{1}=\frac{-\alpha(n-1) b_{1}+\alpha \sum_{j \neq 1} b_{j}}{n+\alpha-1} .
$$

Finally, simple but tedious calculus yields:

$$
V_{1}^{\prime}-V_{1}=\frac{2 \alpha(1-\alpha)^{2}(n-1)\left(\bar{s}_{1}-\underline{s}_{1}\right)}{(n+\alpha-1)\left(n-1-\alpha r_{1}\right)}\left(\sum_{i \in M} b_{i}-m b_{1}\right)-\frac{\alpha(1-\alpha)^{2} m(n-1-\alpha m)\left(\bar{s}_{1}-\underline{s}_{1}\right)^{2}}{\left(n-1-\alpha r_{1}\right)^{2}} .
$$

Hence, in the private-communication game, player 1 of type $s_{1}=\bar{s}_{1}$ does not deviate by lying to players in $M \subseteq R_{1}$ if $V_{1}^{\prime}-V_{1} \leq 0$, i.e.:

$$
-\left(b_{1}-\frac{\sum_{i \in M} b_{i}}{m}\right) \leq \frac{(n-1+\alpha)(n-1-\alpha m)}{2(n-1)\left(n-1-\alpha r_{1}\right)}\left(\bar{s}_{1}-\underline{s}_{1}\right)
$$

Applying the same reasoning, player 1 of type $s_{1}=\underline{s}_{1}$ has no profitable deviation if, for all $M \subseteq R_{1}$, the following condition holds:

$$
b_{1}-\frac{\sum_{i \in M} b_{i}}{m} \leq \frac{(n-1+\alpha)(n-1-\alpha m)}{2(n-1)\left(n-1-\alpha r_{1}\right)}\left(\bar{s}_{1}-\underline{s}_{1}\right)
$$

Condition (4) is obtained from (38) and (39).

\subsection{Other Proofs}

Proof of Corollary 2. We have to show that for every $R_{i}^{\prime \prime} \subseteq R_{i} \cup\{j\}$ we have:

$$
\left|b_{i}-\frac{\sum_{k \in R_{i}^{\prime \prime}} b_{k}}{r_{i}^{\prime \prime}}\right| \leq \frac{(n-1+\alpha)\left(n-1-\alpha r_{i}^{\prime \prime}\right)}{2(n-1)\left(n-1-\alpha\left(r_{i}+1\right)\right)}\left(\bar{s}_{i}-\underline{s}_{i}\right)
$$

If $j \notin R_{i}^{\prime \prime}$, then (4) clearly implies (40), because the LHS are the same in both inequalities, but the RHS is larger in (40). Now, let $R_{i}^{\prime \prime}=R_{i}^{\prime} \cup\{j\}$ for some $R_{i}^{\prime} \subseteq R_{i}$. By (7), the LHS of (40) is smaller than the LHS of (4). Since $r_{i}^{\prime \prime}=r_{i}^{\prime}+1$, it remains for us to check that the RHS of (40) is larger than the RHS of (4), i.e.:

$$
\frac{n-1-\alpha\left(r_{i}^{\prime}+1\right)}{n-1-\alpha\left(r_{i}+1\right)} \geq \frac{n-1-\alpha r_{i}^{\prime}}{n-1-\alpha r_{i}} \Longleftrightarrow \alpha^{2}\left(r_{i}-r_{i}^{\prime}\right) \geq 0
$$

which is satisfied since $r_{i} \geq r_{i}^{\prime}$.

Proof of Corollary 5. Let $T_{i}=R_{i} \cup \tilde{R}_{i}$. For $T_{i}^{\prime} \subseteq T_{i}$, let $R_{i}^{\prime} \subseteq R_{i}$ and $\tilde{R}_{i}^{\prime} \subseteq \tilde{R}_{i}$ be such that $T_{i}^{\prime}=R_{i}^{\prime} \cup \tilde{R}_{i}^{\prime}$. Since $R_{i}$ and $\tilde{R}_{i}$ do not overlap, we have:

$$
\left|b_{i}-\frac{\sum_{k \in T_{i}^{\prime}} b_{k}}{t_{i}^{\prime}}\right| \leq \max \left\{\left|b_{i}-\frac{\sum_{k \in R_{i}^{\prime}} b_{k}}{r_{i}^{\prime}}\right|,\left|b_{i}-\frac{\sum_{k \in \tilde{R}_{i}^{\prime}} b_{k}}{\tilde{r}_{i}^{\prime}}\right|\right\}
$$


Since $R_{i}$ and $\tilde{R}_{i}$ are equilibrium sets of receivers, Proposition 3 implies:

$$
\begin{aligned}
& \left|b_{i}-\frac{\sum_{k \in T_{i}^{\prime}} b_{k}}{t_{i}^{\prime}}\right| \leq \max \left\{\frac{(n-1+\alpha)\left(n-1-\alpha r_{i}^{\prime}\right)}{2(n-1)\left(n-1-\alpha r_{i}\right)}\left(\bar{s}_{i}-\underline{s}_{i}\right), \frac{(n-1+\alpha)\left(n-1-\alpha \tilde{r}_{i}^{\prime}\right)}{2(n-1)\left(n-1-\alpha \tilde{r}_{i}\right)}\left(\bar{s}_{i}-\underline{s}_{i}\right)\right\} \\
& \leq \max \left\{\frac{(n-1+\alpha)\left(n-1-\alpha\left(r_{i}^{\prime}+\tilde{r}_{i}\right)\right)}{2(n-1)\left(n-1-\alpha\left(r_{i}+\tilde{r}_{i}\right)\right)}\left(\bar{s}_{i}-\underline{s}_{i}\right), \frac{(n-1+\alpha)\left(n-1-\alpha\left(\tilde{r}_{i}^{\prime}+r_{i}\right)\right)}{2(n-1)\left(n-1-\alpha\left(r_{i}+\tilde{r}_{i}\right)\right)}\left(\bar{s}_{i}-\underline{s}_{i}\right)\right\} \\
& \leq \frac{(n-1+\alpha)\left(n-1-\alpha t^{\prime} i\right)}{2(n-1)\left(n-1-\alpha t_{i}\right)}\left(\bar{s}_{i}-\underline{s}_{i}\right),
\end{aligned}
$$

where the last inequality comes from $r_{i}^{\prime}+\tilde{r}_{i} \geq t_{i}^{\prime}$ and $\tilde{r}_{i}^{\prime}+r_{i} \geq t_{i}^{\prime}$. Hence, by Proposition $3, R_{i} \cup \tilde{R}_{i}$ is an equilibrium set of receivers for player $i$.

\section{References}

Alonso, R., W. Dessein, and N. Matouschek (2008): "When Does Coordination Require Centralization?" American Economic Review, 98, 145-179.

Ambrus, A. And S. Takahashi (2008): "Multi-Sender Cheap Talk with Restricted State Space," Theoretical Economics, 3, 1-27.

Angeletos, G.-M. And A. Pavan (2007): "Efficient Use of Information and Social Value of Information," Econometrica, 75, 1103-1142.

Battaglini, M. (2002): "Multiple Referrals and Multidimensional Cheap Talk," Econometrica, 70, 1379-1401.

Bulow, J. And P. Klemperer (2002): "Prices and the Winner's Curse," Rand Journal of Economics, 33, 1-21.

Calvó-Armengol, A. And J. D. Martí (2007): "Communication Networks: Knowledge and Decisions," American Economic Review Papers and Proceedings, 97, 1-6.

(2009): "Information Gathering in Organizations: Equilibrium, Welfare and Optimal Network Structure," Journal of the European Economic Association, 7, 116-161.

Chwe, M. S.-Y. (2000): "Communication and Coordination in Social Networks," Review of Economic Studies, 67, 1-16.

Crawford, V. P. And J. Sobel (1982): "Strategic Information Transmission," Econometrica, 50, 1431-1451.

Desgranges, G. And C. Rochon (2007): "Conformism, Public News and Market Efficiency," mimeo.

Dessein, W. (2002): "Authority and Communication in Organizations," Review of Economic Studies, 69, 811-832.

Dewan, T. And D. P. Myatt (2008): "Qualities of Leadership: Communication, Direction and Obfuscation," American Political Science Review, forthcoming. 
Farrell, J. and R. Gibbons (1989): "Cheap Talk with Two Audiences," American Economic Review, 79, 1214-1223.

Forges, F. (2007): "Correlated Equilibrium and Communication in Games," in Encyclopedia of Complexity and Systems Science, ed. by R. Meyers, Springer.

Jackson, M. (2007): Network Formation, The New Palgrave Dictionary of Economics and the Law, MacMillan Press, forthcoming.

Jackson, M. O. And A. Wolinsky (1996): "A Strategic Model of Social and Economic Networks," Journal of Economic Theory, 71, 44-74.

JeHIEL, P. (1999): "Information Aggregation and Communication in Organizations," Management Science, 45, 659-669.

Krishna, V. And J. Morgan (2001): "A Model of Expertise," Quarterly Journal of Economics, $116,747-775$.

Levin, D. (2004): "The Competitiveness of Joint Bidding in Multi-Unit Uniform-Price Auctions," Rand Journal of Economics, 35, 373-385.

Levy, G. And R. Razin (2004): "It Takes Two: An Explanation for the Democratic Peace," Journal of the European Economic Association, 2, 1-29.

Mares, V. and R. M. Harstad (2003): "Private information revelation in common-value auctions," Journal of Economic Theory, 109, 264-282.

Marschak, J. And R. Radner (1972): Economic Theory of Teams, New Haven and London, Yale University Press.

Morgan, J. And P. Stocken (2008): "Information Aggregation in Polls," American Economic Review, 98, 864-896.

Morris, S. And H. S. Shin (2002): "Social Value of Public Information," American Economic Review, 92, 1521-1534.

(2007): "Optimal Communication," Journal of the European Economic Association Papers and Proceedings, 5, 594-602.

RADner, R. (1993): "The Organization of Decentralized Information Processing," Econometrica, $61,1109-1146$.

Rantakari, H. (2008): "Governing Adaptation," Review of Economic Studies, 75, 1257-1285. 